The University of Southern Mississippi

The Aquila Digital Community

Faculty Publications

$9-1-2012$

\title{
Quaternary Ammonium Silane-Functionalized, Methacrylate Resin Composition With Antimicrobial Activities and Self-Repair Potential
}

\author{
Shi-qiang Gong \\ Huazhong University of Science and Technology \\ Li-na Niu \\ Fourth Military Medical University \\ Lisa K. Kemp \\ University of Southern Mississippi \\ Cynthia K.Y. Yiu \\ University of Hong Kong, ckyyiu@hkucc.hku.hk \\ Heonjune Ryou \\ University of Maryland Baltimore County \\ Perforexthpagrefordaftlitianaloakthar:Shttps://aquila.usm.edu/fac_pubs \\ Part of the Biomaterials Commons
}

\section{Recommended Citation}

Gong, S., Niu, L., Kemp, L. K., Yiu, C. K., Ryou, H., Qi, Y., Blizzard, J. D., Nikonov, S., Brackett, M. G., Messer, R. L., Wu, C. D., Mao, J., Brister, L., Rueggeberg, F. A., Arola, D. D., Pashley, D. H., Tay, F. R. (2012). Quaternary Ammonium Silane-Functionalized, Methacrylate Resin Composition With Antimicrobial Activities and Self-Repair Potential. Acta Biomaterialia, 8(9), 3270-3282.

Available at: https://aquila.usm.edu/fac_pubs/250

This Article is brought to you for free and open access by The Aquila Digital Community. It has been accepted for inclusion in Faculty Publications by an authorized administrator of The Aquila Digital Community. For more information, please contact Joshua.Cromwell@usm.edu. 


\section{Authors}

Shi-qiang Gong, Li-na Niu, Lisa K. Kemp, Cynthia K.Y. Yiu, Heonjune Ryou, Yi-pin Qi, John D. Blizzard,

Sergey Nikonov, Martha G. Brackett, Regina L.W. Messer, Christine D. Wu, Jing Mao, L. Bryan Brister,

Frederick A. Rueggeberg, Dwayne D. Arola, David H. Pashley, and Franklin R. Tay 


\title{
Quaternary ammonium silane-functionalized, methacrylate resin composition with antimicrobial activities and self-repair potential
}

\author{
Shi-qiang Gong ${ }^{a}, \dagger$, Li-na Niu ${ }^{b, \dagger}$, Lisa K. Kemp ${ }^{c}$, Cynthia K.Y. Yiu ${ }^{d}$, Heonjune Ryou ${ }^{e}$, Yi-pin \\ Qi $^{f}$, John D. Blizzardg, Sergey Nikonov ${ }^{h}$, Martha G. Brackett ${ }^{\mathrm{h}}$, Regina L.W. Messer ${ }^{\mathrm{h}}$, \\ Christine D. Wu', Jing Mao a, L. Bryan Bristerc, Frederick A. Rueggeberg ${ }^{\mathrm{h}}$, Dwayne D. \\ Arola $^{\mathrm{e}}$, David H. Pashley ${ }^{\mathrm{h}}$, and Franklin R. Tay ${ }^{\mathrm{h},{ }^{*}}$ \\ aTongji Hospital, Huazhong University of Science and Technology, Wuhan, China \\ ${ }^{b}$ Fourth Military Medical University, Xi'an, China \\ cMississippi Polymer Institute, The University of Southern Mississippi, Mississippi, USA \\ dThe University of Hong Kong, Hong Kong SAR, China \\ eUniversity of Maryland Baltimore County, Baltimore, Maryland, USA \\ fSun Yat-sen University, Guangzhou, China \\ gQuadsil Inc., Midland, Michigan, USA \\ hGeorgia Health Sciences University, Augusta, Georgia, USA \\ iUniversity of Illinois at Chicago, Illinois, USA
}

\section{Abstract}

\begin{abstract}
Design of antimicrobial polymers for enhancing healthcare issues and minimizing environmental problems is an important endeavor with both fundamental and practical implications. Quaternary ammonium silane-functionalized methacrylate (QAMS) represents an example of antimicrobial macromonomers synthesized by a sol-gel chemical route; these compounds possess flexible Si-OSi bonds. In present work, a partially-hydrolyzed QAMS copolymerized with bis-GMA is introduced. This methacrylate resin was shown to possess desirable mechanical properties with both a high degree of conversion and minimal polymerization shrinkage. Kill-on-contact microbiocidal activities of this resin were demonstrated using single-species biofilms of Streptococcus mutans (ATCC 36558), Actinomyces naeslundii (ATCC 12104) and Candida albicans (ATCC 90028). Improved mechanical properties after hydration provided the proof-ofconcept that QAMS-incorporated resin exhibits self-repair potential via water-induced condensation of organic modified silicate (ormosil) phases within the polymerized resin matrix.
\end{abstract}

(C) 2012 Acta Materialia Inc. Published by Elsevier Ltd. All rights reserved.

"Corresponding author: Dr. Franklin R. Tay, School of Graduate Studies, Georgia Health Sciences University, Augusta, GA 30912-1129, USA. Tel.: +1 706721 2033; Fax: +1 706721 6252; ftay@georgiahealth.edu.

${ }^{\dagger}$ These two authors contributed equally to this work

Publisher's Disclaimer: This is a PDF file of an unedited manuscript that has been accepted for publication. As a service to our customers we are providing this early version of the manuscript. The manuscript will undergo copyediting, typesetting, and review of the resulting proof before it is published in its final citable form. Please note that during the production process errors may be discovered which could affect the content, and all legal disclaimers that apply to the journal pertain. 


\section{Keywords}

Quaternary ammonium; Organic modified silicate; Antimicrobial; Sol-gel technique; Self-repair

\section{Introduction}

Antimicrobial polymers fulfill rising concerns from industrial, healthcare and consumer enduse sectors regarding infections and contamination [1]. The global demand for healthcare antimicrobial polymers was 15,500 metric tons in 2007 [2] and is forecast to reach 221,758 metric tons by 2017, with emphasis on technological advancements that are more ecofriendly and non-toxic to humans [3].

Polymeric biocides may be made by grafting an antimicrobial agent to their surfaces or blending with a nonleaching biocide [1]. Because of the presence of reactive silanol groups generated during hydrolysis, quaternary ammonium silanes can attach covalently to substrate surfaces via Si-O linkages to exert non-migrating microbiocidal functions [4]. Due to its low toxicity, 3-(trimethoxysilyl)propyldimethyloctadecyl ammonium chloride (SiQAC), a organofunctional trialkoxysilane, has been used in antimicrobial coatings of medical devices [5,6]. The antimicrobial activity of this compound is attributed to the long, lipophilic $-\mathrm{C}_{18} \mathrm{H}_{37}$ alkyl chain that penetrates bacterial cell membranes to produce leakage, autolysis and cell death of bacteria that come in direct contact [7]. The disadvantage of a surface attachment/grafting approach is that antimicrobial activity is lost after the surface layer is worn off. This disadvantage can be eliminated by incorporated SiQAC into the bulk resin rather than using it as a coating.

Although silane-based sol-gel chemistry has been used for preparing quaternary ammonium silane-based antimicrobial polymers, such processes do not result in macromonomers with polymerizable end-functional groups [8]. A facile, generic scheme for immobilizing SiQAC on macromonomers has recently been developed [9]. This scheme represents a specific application of the sol-gel route to produce Class II hybrid inorganic-organic materials (i.e. components linked by covalent/ionic bonds) [10]. By using tetra-alkoxysilane as the anchoring unit for $\mathrm{SiQAC}$ and other organofunctional trialkoxysilanes (e.g. vinyl, epoxy, isocyanato or methacryloxy functionalities) in a mix-and-match approach (Supplementary Information S1), different end-functional macromonomers may be synthesized with permanent, nonleaching microbiocidal activities that are independent of the loss of the surface layer, as the activity has been incorporated throughout the product. Other metal alkoxides (e.g. Ti, Al, Sn, Zr) may be used in lieu of silicon alkoxides, as dictated by specific product requirements. Such an approach represents an alternative strategy for synthesizing antimicrobial macromonomers, without using multi-step polymerization techniques that require additional catalysts and difficult purification procedures [11]. The disadvantage of the sol-gel process versus controlled polymerization techniques is its lack of precise control over polymer polydispersity and architecture [10]. Nevertheless, polymers prepared from SiQAC-functionalized macromonomers may have improved toughness and damping properties, due to the flexibility of the siloxane backbone as compared with rigid C-C bonds [12].

In the present work, a methacryloxy version of the aforementioned sol-gel process is used to produce a new class of methacrylate macromonomers - quaternary ammonium methacryloxy siloxanes (QAMS). Specifically, a trifunctional QAMS (QAMS-3) containing SiQAC, tetraethoxysilane (TEOS) and 3-methacryloxypropyltrimethoxysilane (3-MPTS) in a molar ratio of 1:1:3 was synthesized and solubilized in methanol. By altering the $\mathrm{pH}$ value of the system, hydrolysis and condensation reactions of QAMS-3 could be differentially 
controlled. Completely-hydrolyzed (QAMS-3 ${ }_{\mathrm{CH}}$ ) and partially-hydrolyzed versions (QAMS-3 $3_{\mathrm{PH}}$ ) of QAMS-3 could be attained by using stoichiometric molar concentrations of water to target complete (16 moles) or 50\% hydrolysis ( 8 moles).

For thermoset organic polymers, water sorption results in plasticization of the polymer network, lowering of glass transition temperatures and deterioration in mechanical properties [13]. Water sorption is also expedited in the presence of functional stresses [14]. By controlling the degree of hydrolysis and $\mathrm{pH}$, QAMS- $3 \mathrm{PH}$ may be blended with methacrylate resin monomers to produce advanced copolymer blends with self-repair potential. This goal is accomplished via water sorption-induced continuation of the hydrolysis and condensation reactions, as the material functions in an aqueous environment at physiologic $\mathrm{pH}$ to deposit three-dimensional (3-D) organic modified silicates (ORMOSIL) within the copolymer matrix. Although self-healing mechanisms have been proposed for epoxy resins in response to micro-cracking induced by hydrolytic and mechanical stresses, such mechanisms are lacking for methacrylate resins [15].

For proof-of-concept, QAMS-3 $\mathrm{PH}_{\mathrm{H}}$ was blended with 2,2-[4(2-hydroxy 3methacryloxypropoxy)-phenyl]propane (bis-GMA) to create visible light-curable comonomer blends to test the hypotheses that: 1) antimicrobial activities are retained after copolymerization of QAMS-3 $\mathrm{PH}$ with bis-GMA, and 2) nanodynamic mechanical properties of the polymerized resin blend are improved after water sorption.

\section{Materials and methods}

\subsection{Sol-gel reaction of Quaternary Ammonium Methacrolxy Siloxane (QAMS)}

Tetraethoxysilane, SiQAC and 3-MPTS were obtained from Sigma-Aldrich (St. Louis, MN, USA) and used without further purification. The SiQAC was supplied in $42 \mathrm{wt} \%$ methanol. For the preparation of QAMS-3 monomer mix, TEOS, SiQAC and 3-MPTS were mixed in a molar ratio of 1:1:3 and frozen at $-70^{\circ} \mathrm{C}$ until use. QAMS- $3_{\mathrm{CH}}$ and QAMS- $3_{\mathrm{PH}}$ versions were prepared at ambient temperature by adding stoichiometric molar concentrations of MilliQ water (resistivity $18.2 \mathrm{~m} \Omega-\mathrm{cm}$ ) to the QAMS-3 monomer mix to target complete (16 moles) and 50\% hydrolysis ( 8 moles) with the assumption that negligible water was produced from condensation. Hydrolysis reactions were conducted at $\mathrm{pH} 2.5$ by adding $1 \mathrm{~N}$ $\mathrm{HCl}$ to the MilliQ water. Condensation reactions were conducted at $\mathrm{pH} 7.4$ by adding sufficient $1 \mathrm{~N} \mathrm{NaOH}$ to the acidified MilliQ water, to adjust the $\mathrm{pH}$ to these values while constantly monitoring the $\mathrm{pH}$ of the mixture with a combination $\mathrm{pH}$ electrode.

\subsection{Nuclear Magnetic Resonance (NMR) characterization of completely-hydrolyzed QAMS-3}

The structures of the non-hydrolyzed QAMS-3 monomer mix, hydrolyzed QAMS-3 and products after condensation were characterized by ${ }^{1} \mathrm{H},{ }^{13} \mathrm{C}$ and ${ }^{29} \mathrm{Si}$ NMR. Proton and carbon spectra were obtained using a Varian Mercury NMR spectrometer (Varian Inc., Palo Alto, CA, USA) operating at a frequency of $300.13 \mathrm{MHz}$. Samples were prepared by diluting with $\mathrm{CDCl}_{3}$ to approximately 10 mass\% sample concentration. Reaction solvents were not removed from the QAMS-3 samples to avoid potential changes in hydrolysis and condensation levels. Typical proton acquisition parameters were 2 second recycle delay, an $8.2 \mathrm{~ms}$ pulse corresponding to a $45^{\circ}$ flip angle, an acquisition time of 2 seconds, and 32 scans per sample. All shifts were referenced manually using the resonance frequency of $\mathrm{CDCl}_{3}$. Typical carbon acquisition parameters were a 2 second recycle delay, an $8.4 \mathrm{~ms}$ pulse width corresponding to a $45^{\circ}$ flip angle, and an acquisition time of 1.8 seconds. The number of scans acquired for each sample was 256 . Composite pulse decoupling was used to remove proton coupling, and all shifts were referenced manually using the resonance frequency of $\mathrm{CDCl}_{3}$. Silicon spectra were obtained using a Bruker Avance III NMR 
spectrometer (Buker AXS Inc., Madison, WI, USA) operating at a frequency of 119.23 $\mathrm{MHz}$. Acquisition parameters included a pre-scan delay of 174.34 seconds and an acquisition time of 0.66 seconds, yielding a 175 second delay between transients. The 90o pulse width was $14 \mu \mathrm{s}$, with the number of accumulated scans ranging from 256 to 512 for each sample. Composite pulse decoupling was used to remove proton coupling, with the ${ }^{1} \mathrm{H}$ decoupler gated off between scans to prevent negative NOE enhancements. Background signal from glass was removed by using Teflon NMR tubes in the place of traditional glass tubes as well as implementing the DEPTH pulse sequence [16]. Peak referencing was done externally using the glass peak for spectra acquired using routine NMR tubes $(-115.0 \mathrm{ppm})$.

\subsection{ATR-FTIR characterization of completely-hydrolyzed and partially-hydrolyzed QAMS-3}

A Nicolet 6700 Fourier transform-infrared (FT-IR) spectrophotometer (Thermo Scientific, Waltham, MA, USA) with an attenuated total reflection (ATR) setup was used to collect infrared spectra between $4,000-400 \mathrm{~cm}^{-1}$ at $4 \mathrm{~cm}^{-1}$ resolution using the average of 32 scans. Infrared spectra of the monomer mix for preparing QAMS-3, after partial hydrolysis of the monomer mix at $\mathrm{pH} 2.5$ and after condensation at $\mathrm{pH} 7.4$ were taken. Because no photoinitiator was used in the material prepared for ATR-FTIR, the normalized spectra were superimposed with respect to the aliphatic $\mathrm{C}=\mathrm{C}$ band of the methacryloxy groups at 1636 $\mathrm{cm}^{-1}$. The hydrolysis and condensation kinetics of completely-hydrolyzed QAMS-3

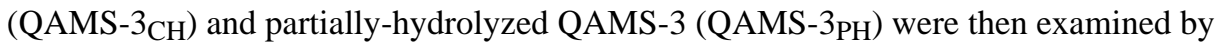
taking IR spectra at designated time intervals up to $240 \mathrm{~min}$. The hydrolysis kinetics of QAMS- $3 \mathrm{CH}$ and QAMS-3 $\mathrm{PH}$ were monitored at $\mathrm{pH} 2.5$. Changes in peak height over time were plotted for the Si-O-C band at $1082 \mathrm{~cm}^{-1}$ and Si-OH band at $914 \mathrm{~cm}^{-1}$. After hydrolysis had reached 50 or $100 \%$, the $\mathrm{pH}$ of the reaction mixture was changed from 2.5 to 7.4 to allow condensation polymerization to proceed. The condensation kinetics of QAMS-3 ${ }_{\mathrm{CH}}$ and QAMS-3 $3_{\mathrm{PH}}$ were monitored at $\mathrm{pH}$ 7.4. Changes in peak height over time were plotted for Si-O-Si band at $1117 \mathrm{~cm}^{-1}$ and $\mathrm{Si}-\mathrm{OH}$ band at $914 \mathrm{~cm}^{-1}$.

\subsection{Polymerization characteristics}

Bis-GMA was a gift from Esstech, Inc. (Essington, PA, USA). Triethylene glycol dimethacrylate (TEGDMA), camphorquinone and ethyl(4-dimethylamino)benzoate were purchased from Sigma-Aldrich. QAMS-3 $\mathrm{PH}_{\mathrm{H}}$ was in solvated form containing 32.1\% methanol derived from the monomer mix. A series of 5 comonomer blends was prepared with the molar ratios of bis-GMA:TEGDMA:QAMS-3 $\mathrm{PH}=70: 30: 0$ (control), 70:20:10, 70:10:20, 70:5:25 and 70:0:30. For each comonomer blend, 0.5\% camphorquinone and 1\% ethyl(4-dimethylamino)benzoate were used as photoinitiator and accelerator, respectively. Addition free radical polymerization of these resins could be achieved by photo-curing with visible light in the wavelengths range of 410-500 $\mathrm{nm}$ (absorption maximum of camphorquionone $=465 \mathrm{~nm}$ ) [17]. Each resin comonomer blend was homogenized and kept in light-tight bottles until use.

Kinetics of monomer conversion: Uncured resin from each of the 5 comonomer blends was placed as a thin film $(\approx 0.15 \mathrm{~mm})$ and covered with Mylar to prevent oxygen inhibition. Light-curing was performed for 60 seconds, using a quartz-tungsten-halogen photo-curing source (Optilux 501, Demetron Research, Danbury, CT, USA) with an output intensity of $600 \mathrm{~mW} / \mathrm{cm}^{2}$. Real-time conversion was followed for a total of 600 seconds from time of light initiation. One spectrum per second was obtained at a resolution of $2 \mathrm{~cm}^{-1}$. Conversion was determined using conventional methods of observing changes in the ratio of the aliphatic-to-aromatic $\mathrm{C}=\mathrm{C}$ absorption ratios at $1636 \mathrm{~cm}^{-1}$ to aromatic $\mathrm{C}=\mathrm{C}$ ratios at 1508 $\mathrm{cm}^{-1}$ in the uncured and cured states [18]. Specimen temperature was controlled at $25^{\circ} \mathrm{C}$ prior to light-curing. Spectra were obtained using an ATR unit on a horizontal, diamond stage in a FT-IR spectrometer (FTS-40, Digilab/BioRad, Cambridge, MA, USA) [19]. Five 
replications were made for each comonomer blend $(\mathrm{N}=5)$, each consisting of 605 scans, representing 5 seconds of scans prior to light-activation, and 600 scans subsequent to the curing light being turned on. The degree of conversion $(\%)$ and the cure rate $(\% /$ second) for each comonomer blend were plotted against curing time. The degree of conversion at maximum cure rate of the five comonomer blends were statistically analyzed using one-way analysis of variance (ANOVA) and Tukey mulitple-comparison tests at $a=0.05$, after validating the normality and equal variance assumptions of the data.

Kinetics of polymerization shrinkage: The same set-up used for obtaining monomer conversion was used for determining volumetric real-time shrinkage so that direct comparison of the results could be made between the two test parameters. Linear shrinkage strain of each of the 5 comonomer blends was measured at $25^{\circ} \mathrm{C}$ over a period of 600 seconds, at the rate of one measurement/second, using the "deflecting disk" method $(\mathrm{N}=5)$ [20]. The data were converted into volumetric shrinkage (\%). Statistical analysis of the volumetric shrinkage of the 5 comonomer blends was performed using Kruskal-Wallis ANOVA and Dunn's multiple comparison tests at $a=0.05$. Shrinkage rates were obtained by differentiation of the shrinkage strain data with respect to time. Non-linear regression analysis was performed to correlate the maximum shrinkage rate of each comonomer blend with the concentration of QAMS-3 present in the comonomer blend.

\subsection{Contact angle measurement}

Polymerized resin disks $(6 \pm 0.1 \mathrm{~mm}$ diameter, $1 \pm 0.1 \mathrm{~mm}$ thick; $\mathrm{N}=5)$ were fabricated for each copolymer blend using a Teflon split ring mold between two glass plates covered with Mylar films. The resin was polymerized for 60 seconds using the Optilux 501 light-curing unit (Kerr Corp., Orange CA, USA). The EasyDrop DSA-20 device (Krüss, Hamburg, Germany) was used to measure contact angles of milliQ water $(5 \mu \mathrm{L})$ dispensed on each resin disk surface. Digital video files were recorded of the silhouette of the surface profile of each water droplet at the rate of 1 image per second for 60 seconds. Static contact angles at each time interval was calculated using the software supplied with the device. For each resin disk, the static contact angle obtained at 30 seconds was taken as the equilibrium contact angle. The data obtained from the 5 comonomer blends were statistically analyzed using one-way ANOVA and Tukey multiple comparison tests at $a=0.05$.

\subsection{Thermogravimetric analysis}

Two comonomer blends with the molar ratios of bis-GMA:TEGDMA:QAMS-3PH $=70: 30: 0$ (control) and 70:0:30 (experimental) were used to prepare polymerized resins in the manner described previously. Thermogravimetric analysis was performed with a Q500

thermogravimetric analyzer (TA Instruments, New Castle, DE, USA). Approximately $25 \mathrm{mg}$ of the control or experimental polymerized resin was placed in a platinum pan and heated at a rate of $10^{\circ} \mathrm{C} / \mathrm{min}$ from ambient temperature to $600^{\circ} \mathrm{C}$ in nitrogen, and from $600-1000^{\circ} \mathrm{C}$ in atmospheric air to remove the carbon residues. The data were analyzed using the Universal Analysis 2000 software (TA Instruments) and expressed as mass loss $v s$ temperature as well as derivative mass loss $v s$ temperature.

\subsection{Viability of biofilms}

Streptococcus mutans (ATCC 36558, ATCC, Manassas, VA, USA) and Actinomyces naeslundii (ATCC 12104) were cultured in Brain Heart Infusion (BHI) broth (Difco, Becton-Dickinson and Co., Sparks, MD, USA). Candida albicans (ATCC 90028) was cultured in Yeast Nitrogen Base (YNB; Difco) supplemented with $50 \mathrm{mM}$ glucose. Microorganism suspensions were prepared from 16-hour fresh cultures and stored at $4{ }^{\circ} \mathrm{C}$ with continuous gentle stirring until use. Polymerized resin disks were prepared from 3 comonomer blends with bis-GMA:TEGDMA:QAMS-3 $\mathrm{PH}_{\mathrm{PH}}=$ 70:30:0 (control), 70:10:20 and 
70:0:30 ( $\mathrm{N}=5)$. The disks were disinfected under ultraviolet light for 2 hours. Each microorganism was grown separately in a bioreactor that consisted of a reactor vessel and a magnetic holder for continuous mixing. Resin disks from each comonomer group were affixed to the sample ports of the magnetic stir disk. The reactor vessel was filled with the respective micro-organism suspension at a concentration of $10^{7}$ cells $/ \mathrm{mL}$. Each microorganism was prepared in the respective culture medium that was supplemented with $50 \mathrm{mM}$ glucose. Incubation was performed at $37^{\circ} \mathrm{C}$ for 90 minutes in an orbital shaker incubator to develop the initial adhesion phase of the biofilm. The magnetic stir disk was then aseptically transferred to a second sterile reactor vessel that contained $200 \mathrm{~mL}$ of the respective nutrient medium. This vessel was placed in the orbital shaker incubator and connected to a nutrient bottle, waste bottle and an infusion pump to complete the in vitro chemostat setup. Flow rate of the nutrient medium was established in chemostat mode at a dilution rate of $0.10 \mathrm{~h}^{-1}$. Biofilm formation was allowed to proceed for $48 \mathrm{~h}$ to the maturation phase. Biofilmcontaining resin disks were aseptically removed and immersed in sterile phosphate-buffered saline to remove non-adherent micro-organisms. Growth of the biofilms was assessed by BacLight LIVE/DEAD viability kit (Molecular Probes, Eugene, OR, USA). Live cells with intact membranes were stained green and dead cells with damaged membranes were stained red. Resin discs with biofilms were placed on glass slides and imaged with a CSLM (Fluoview FV 1000, Olympus, Tokyo, Japan). The intensities of SYTO9 (green) and propidium iodide fluorescence (red) were monitored at 480/500 nm and 488-540/617 nm, respectively. Each image stack had a substratum coverage field area of $215 \mu \mathrm{m} \times 215 \mu \mathrm{m}$. The $z$-step for images in a stack was $2 \mu \mathrm{m}$ and ten 2-D images were acquired for each biofilm. Ten $z$-stacks (scans taken from the $z$-axis) were acquired from each of the five resin disks from a comonomer group. The live/dead ratio of biofilm cells from an overlay projection of a $z$-stack was quantified using the Leica Qwin image analysis software (Leica Microsystems Inc., Buffalo Groove, IL, USA). Viability was expressed as the percentage of live and dead cells obtained by determining the ratio between the red or green threshold voxels and the total threshold voxels of each image [21]. The mean value obtained from the $10 z$-stacks of a resin disk was used to represent the percentages of live and dead microorganisms for that disk. Each species of micro-organisms was analyzed separately for the percentages of live micro-organisms in the three comonomer groups. As the normality and equal assumptions of the data were violated, data for each species were analyzed with Krukal-Wallis ANOVA and Dunn's multiple comparison tests at $a=0.05$. Threedimensional images of $z$-stacks of interest were reconstructed to qualitatively identify the killing characteristics of QAMS-3 $\mathrm{PH}^{-}$-containing resins within the biofilm.

\subsection{Cytotoxicity testing}

A mouse apical papilla-derived odontoblast-like cell line (MDPC-23), a gift from Professor Jacques Nör, was employed for evaluation, as this cell line has been used extensively for cytotoxicity testing of bis-GMA- and TEGDMA-containing resins [22]. The cells were incubated at $37^{\circ} \mathrm{C}$ in humidified $5 \% \mathrm{CO}_{2}$. The culture medium consisted of a-MEM (Gibco, Invitrogen Corp, Carlsbad, CA, USA) and 10\% fetal bovine serum, supplemented with 2 $\mathrm{mM} \mathrm{L}$-glutamine, $100 \mathrm{U} / \mathrm{mL}$ penicillin and $100 \mu \mathrm{g} / \mathrm{mL}$ streptomycin. Cells were plated at $1 \times 10^{4}$ cells $/ \mathrm{cm}^{2}$ in $1.0 \mathrm{~mL}$ of culture medium in $24-$ well plates.

Polymerized disks from the 5 comonomer groups were prepared as previously described. Disks prepared from poly(methyl methacrylate) (PMMA) were used as the positive control. Teflon disks were used as the negative control. Both the resin disks and eluents from the resin disks were evaluated in 2 weekly cycles. For evaluation of resin disks $(\mathrm{N}=12)$ in one cycle, each disk was placed individually in transwell inserts with a $0.4 \mu \mathrm{m}$ pore size (Corning Incorporated Life Sciences, Lowell, MA, USA) to avoid direct cell contact and exposed to the plated cells for 3 days before testing. For evaluation of eluted resin 
components in one cycle, resin disks in each group were incubated at $37{ }^{\circ} \mathrm{C}$ with the culture medium ( 2 disks $/ \mathrm{mL}$; i.e. $\mathrm{N}=6$ ) for 4 days to produce resin extract concentrates. Each concentrate was diluted with fresh culture medium to 1:10 of its original concentration. The diluted media containing the respective resin eluents were then exposed to the plated cells for 3 days before testing. This cycle was repeated in the same manner during the second week.

Cell viability assay: Succinic dehydrogenase (SDH) activity of the cells was determined using MTT assay [23]. Retrieved cells were incubated in an MTT-succinate solution for 60 minutes and xed with Tris-formalin. The MTT formazan in the cells was dissolved in-situ using dimethyl sulfoxide- $\mathrm{NaOH}$, and the optical density was measured using a microplate reader at $562 \mathrm{~nm}$. The formazan content of each well was computed as a percentage of the mean of the Te on controls, which was taken to represent $100 \%$ biocompatibility. The SDH activities of the resin disks and the eluents at each cycle were statistically analyzed separately, using Krusal-Wallis ANOVA and Dunn's multiple comparison tests against the Teflon control, at $a=0.05$.

Flow cytometry: Additional polymerized resin disks with bis-GMA:TEGDMA:QAMS-3 $\mathrm{PH}$ $=70: 30: 0$ (control), 70:10:20 and 70:0:30 were used for evaluation. After incubation of the cells with the resin disks for 3 days in the first cycle, the cells were detached from the wells with $0.25 \%$ trypsin. They were stained with an Apoptosis \& Necrosis Quantification Kit (Biotium, Hayward, CA, USA), using FITC-Annexin V (AnV; $\left.\lambda_{\mathrm{abs}} / \lambda_{\mathrm{em}}=492 / 514 \mathrm{~nm}\right)$ and ethidium homodimer-III (Etd-III; $\lambda_{\mathrm{abs}} / \lambda_{\mathrm{em}}=528 / 617 \mathrm{~nm}$ ) as the fluorescence stains for cytoplasmic membrane phospholipids and nucleic acids in nucleus-permeable non-vital cells, respectively. The stained cells were sorted with a FACSCalibur flow cytometer (BD Biosciences, Franklin Lakes, NJ, USA) to determine the percentage distribution of viable (AnV/Etd-III negative), early apoptotic (AnV positive, Etd-III negative), late apoptotic (AnV/Etd-III positive) and necrotic cells (AnV negative, Etd-III positive) after exposure to the three comonomer resin disks, the positive PMMA control, or the Teflon negative control.

Two-photon laser fluorescence microscopy: MDPC-23 cells plated at $2000 / \mathrm{cm}^{2}$ onto coverslips in 6-well plates were established for 3 days. Undiluted eluents $(2 \mathrm{~mL})$ derived from the positive and negative controls and from polymerized resin disks with bisGMA:TEGDMA:QAMS-3 ${ }_{\mathrm{PH}}=70: 30: 0$ (control), 70:10:20 and 70:0:30 were added to the plated cells into each well. After incubating for 3 days with the extract, the cells were tripled stained with Hoeschst $33342\left(\lambda_{\text {abs }} / \lambda_{\text {em }}=350 / 461 \mathrm{~nm}\right.$; blue fluorescence), Etd-III (red fluorescence) and FITC-Annexin V (green fluorescence), for imaging of the morpholgy of cell death (apoptosis $v s$ necrosis) after exposure to the eluents. A two-photon confocal scanning microscope (LSM 510 META, Carl Zeiss, Thornwood, NY, USA) coupled to a MIRA 900 Ti:sapphire laser (Coherent Inc., Santa Clara, CA, USA) was used for imaging. Using these fluorophores in combination, Hoechst 33342, a cell membrane-permeant, minor groove-binding DNA stain, stains the nuclei of both apoptotic and necrotic cells. However, healthy cells are stained by Hoechst only, not by FITC-Annexin V and EtD-III. Apoptotic cells are stained both green and blue. Necrotic cells are stained both red and blue. Cells stained blue, green and red represent dead cells progressing from the apoptotic cell population.

\subsection{Nano-Dynamic Mechanical Analysis}

Polymerized resin disks with bis-GMA:TEGDMA:QAMS- $3_{\mathrm{PH}}=70: 30: 0$ (control), 70:0:30 and 60:0:40 were used for evaluation $(\mathrm{N}=5)$ of the dynamic mechanical behavior of these resins. In addition, bis-GMA and the methanol-solvated QAMS-3 comonomer mix (mass ratio 70:30) were used to prepare resin disks for examination $(\mathrm{N}=5)$. A Triboindenter $(\mathrm{TI}$ 
900, Hysitron, Minneapolis, MN, USA) equipped with a Berkovich diamond indenter with a $100 \mathrm{~nm}$ tip radius was used with Scanning Probe Microscopy (SPM) to determine dynamic mechanical properties. Contact load and displacement signals were monitored and used to obtain surface topography and gradient images. These quantities were used to calculate the phase angle and to generate maps of the complex $(E)$, storage $\left(E^{\prime}\right)$ and loss $\left(E^{\prime \prime}\right)$ moduli, as well as tan $\delta\left(E^{\prime \prime} / E^{\prime}\right)$ values. A $4 \mu \mathrm{N}$ set-point load, a $2 \mu \mathrm{N}$ dynamic loading amplitude and a $100 \mathrm{~Hz}$ loading frequency were employed for evaluating dynamic mechanical behavior under dehydrated and hydrated conditions. Hydration was performed by incubating the resin disks in Hank's balanced salt solution (pH 7.4; Gibco, Life Technologies, Grand Island, NY, USA) at $37^{\circ} \mathrm{C}$ for $72 \mathrm{~h}$. Dynamic sinusoidal loading was applied over areas of $30 \times 30 \mu \mathrm{m}$ with 5 scans/sample and $256 \times 256$ points/scan. Specimens were scanned in the hydrated condition by applying a layer of ethylene glycol over the specimen surface to prevent water evaporation during a typical 25-30 min scanning period [24]. Data generated from the 5 scans of each resin disk were used to generate the mean property value for that disk. Each mechanical property parameter (E, $E^{\prime}$ or $\left.E^{\prime \prime}\right)$ was analyzed separately. The mean property data from the four groups (one control and three experimental) were logarithmically transformed to conform to normality and equal variance assumptions. A two-factor repeated-measures ANOVA was employed to examine the effects of resin composition and hydration modes on the respective material property. Post-hoc comparisons were performed using Tukey multiple comparison tests. Statistical significance for all tests was set at $a=$ 0.05 .

\subsection{Transmission electron microscopy}

Polymerized resin disks were prepared from the comonomer blend with bisGMA:TEGDMA:QAMS-3 ${ }_{\mathrm{PH}}=70: 0: 30$. Biaxial flexure was performed using a universal testing machine (Model 5844, Instron, Canton, MA, USA) to determine the flexural strength of the resin disks [25] (data not shown). Additional polymerized resin disks were subjected to subcritical biaxial flexural stresses (i.e. without causing catastrophic failure) for 1,500 cycles $(5 \mathrm{~Hz}$, stress ratio $\mathrm{R}=0.3$ ), to create surface/subsurface microscopic cracks prior to hydration in Hank's balanced salt solution for 72 hours. Portions of the resin disks that were in contact with the piston used for biaxial cyclic loading were embedded in epoxy resin. Ninety nanometer thick longitudinal sections of the resin disks were prepared with an ultramicrotome and stained with $1 \%$ phosphotungstic acid for 5 minutes. The stained sections were examined with a transmission electron microscope (JSM-1230, JEOL, Tokyo, Japan) at $110 \mathrm{kV}$. Images were recorded using a $4 \mathrm{~K} \times 4 \mathrm{~K}$ Gatan CCD camera.

\section{Results}

Figure 1 represents the reaction scheme for synthesizing QAMS using tetra-alkoxysilane as anchoring unit. In current study, a trifunctional QAMS (QAMS-3) containing SiQAC, tetraethoxysilane (TEOS) and 3-methacryloxypropyltrimethoxysilane (3-MPTS) in a molar ratio of 1:1:3 was synthesized and solubilized in methanol. Similar to SiQAC [26], hydrolysis and condensation reactions of QAMS-3 could be differentially controlled by altering the $\mathrm{pH}$ value of the system. These reactions were characterized by ${ }^{1} \mathrm{H},{ }^{13} \mathrm{C}$ and ${ }^{29} \mathrm{Si}$ NMR (Supplementary Information S2). Both proton and carbon NMR confirmed that the TEOS, SiQAC, and 3-MPTS are nearly completely hydrolyzed at the end of the reaction with water at $\mathrm{pH} 2.5$. Silicon NMR indicated the formation of a new peal at $-58 \mathrm{ppm}$ after hydrolysis, which is consistent with the formation of trifunctional siloxane after one substitution reaction. In addition, peaks in the -90 to $-115 \mathrm{ppm}$ region that were identified after hydrolysis are suggestive of the formation of a loose network via early condensation processes. As the 3- and 4-functionalities in TEOS continued to react, the signals shifted to $-65 \mathrm{ppm}$ and $-75 \mathrm{ppm}$ from SiQAC and 3-MPTS, and from -100 to $-140 \mathrm{ppm}$ from TEOS. These shifts are indicative of further condensation and potential network formation. 
The NMR results were complemented by examination of the kinetics of the hydrolysis and condensation reactions using attenuated total reflection-Fourier transform infrared spectroscopy (Fig. 2A-C). Completely-hydrolyzed (QAMS-3 $\mathrm{CH}_{\mathrm{H}}$ ) and partially-hydrolyzed versions (QAMS-3 $\mathrm{PH}$ ) of QAMS-3 were prepared using stoichiometric molar concentrations of water to target complete (16 moles) or $50 \%$ hydrolysis ( 8 moles). The monomer mix had an initial $\mathrm{pH}$ of approximately 5.5 and was reasonably stable toward hydrolysis and condensation. When the $\mathrm{pH}$ was lowered to 2.5 , rapid hydrolysis occurred with minimal condensation. When the $\mathrm{pH}$ was raised to 7.4 , condensation of the silanol groups resulted in formation of siloxane linkages (polymerization).

Figure 3A shows the kinetics of monomer conversion of the five bis-GMA comonomer blends investigated by real-time ATR-FTIR spectroscopy. Under the same photopolymerization conditions, when TEGDMA in the bis-GMA/TEGDMA mixture was progressively replaced by QAMS- $3_{\mathrm{PH}}$, there was a progressive increase in the degree of conversion (\%), and progressive decrease in the maximum rate of cure $\left(\% \mathrm{sec}^{-1}\right)$. Figure 3B displays the increase in degree of monomer conversion at each time point with respect to increasing QAMS- $3_{\mathrm{PH}}$ concentration. From the cure rate (Fig. 3C), it can be seen that there were two distinct phases in the polymerization process: an auto-acceleration phase and an auto-deceleration phase. Curing of the five comonomer blends peaked at a maximum rate from $9-11 \%$ per second. This peak occurs very early in the conversion process, within the first 3-4 seconds. Figure 3D shows how the degree of conversion at maximum cure rate is affected by the different resins. A clear trend of decreasing conversion at maximal cure rate with respect to increasing QAMS- $3 \mathrm{PH}_{\mathrm{PH}}$ concentration is evident for the materials tested. The five bis-GMA comonomer blends all demonstrated polymerization shrinkage when exposure to visible light (Fig. 4A). With the exception of a light-initiated expansion caused by the heat generated during light exposure, polymerization shrinkage continued to increase until a maximum shrinkage value was achieved for each respective resin. Figure 4B compares the maximum volumetric shrinkage among the five comonomer blends. A progressive reduction in maximum volumetric shrinkage can be seen as TEGDMA was reduced and replaced by an equivalent amount of QAMS-3 $\mathrm{PH}$. Groups that are labeled with the same lower case letters are not statistically different ( $p>0.05$ ). Figure $4 \mathrm{C}$ shows the changes in shrinkage rate with time. Similar to the conversion kinetics, two distinct phases in the polymerization process are evident, with the highest shrinkage rate occurring between 3-5 seconds before auto-deceleration occurred. In Fig. 4D, a powder regression model provides an excellent fit (adjusted $\mathrm{R}^{2}=0.986 ; \mathrm{p}<0.01$ ) for the relation between the maximum shrinkage rate and increases in QAMS-3 $\mathrm{PH}$ concentration.

Equilibrium contact angle measurements of the five polymerized resins indicated that QAMS-3 $\mathrm{PH}$-containing resins were more hydrophobic $\left(74.2-78.0^{\circ}\right)$ than the bis-GMA/ TEGDMA $\left(68.1^{\circ}\right)$ (Supplementary Information S-3). Thermogravimetric profiles and the corresponding derivative mass loss of polymerized resins prepared with bis-GMA/ TEGDMA and bis-GMA/QAMS-3 ${ }_{\mathrm{PH}}$ (mass ratios 70:30) are shown in Supplementary Information S-4. Thermal decomposition of bis-GMA/TEGDMA was characterized by three peaks. The first peak at $298^{\circ} \mathrm{C}$ may be assigned to the decomposition of the free monomers. The second peak at $360^{\circ} \mathrm{C}$ may be attributed to the scission of low molecular weight, thermal decomposition products from the cross-linked bis-GMA and TEGDMA. The third peak at $424^{\circ} \mathrm{C}$ is associated with the decomposition reaction that led to the generation of the low molecular weight decomposition products (methacrylic acid and hydroxyethyl methacrylate) [27]. For the bis-GMA/QAMS- $3_{\mathrm{PH}}$ system, the initial mass loss up to $167^{\circ} \mathrm{C}$ may be attributed to the evaporation of free and bound methanol solvent, as well as volatilization of unreacted components within the monomer mix. The peak at $228^{\circ} \mathrm{C}$ probably represented decomposition of the partially-hydrolyzed QAMS-3, while the peak at $424^{\circ} \mathrm{C}$ is characteristic of the decomposition of bis-GMA [28]. 
Progressive replacement of TEGDMA with QAMS- $3_{\mathrm{PH}}$ is associated with increasing bactericidal and fungicidal activities (Fig. 5A-B). Although biofilm viability was not completely eliminated, the killing characteristics were evident in the 3-D reconstructed biofilm images. The biofilm cell mass in contact with the resin surface were mainly nonviable (red), while viable cells were identified only within biofilm mass above the nonviable base layer (Fig. 5C).

Figure 6 depicts mitochondrial succinic dehydrogenase activities (normalized to Teflon negative control - 100\%) of MDPC-23 cells after exposure to polymerized resin disks prepared from the 5 comonomer blends and PMMA positive control (Fig. 6A), and eluents from the resin disks (1:10 dilution) at the two time-periods (Fig. 6B). Initially cytotoxicity was identified from the resin disks at the first week but not at the second week, after extraction of toxic components from the polymerized resins. By contrast, the eluents derived from these resins were considerably more cytotoxic. However, after the second week cycle, eluents derived from polymerized resins with bis-GMA:TEGDMA:QAMS- $3_{\mathrm{PH}}$ mass ratios of 70:5:25 and 70:0:30 were as biocompatible as the Teflon negative control. Flow cytometry and two-photon laser fluorescence microscopy are consistent with the MTT assay, indicating that progressive reduction in cytotoxicity as TEGDMA was replaced by QAMS-3PH, with the 70/30 mass\% bis-GMA/QAMS-3 $\mathrm{PH}$ resin being as biocompatible as the Teflon negative control after the first week (Fig. 7).

Accordingly, polymerized resin disks prepared from 70:30 mass\% bis-GMA/TEGDMA (control) and an experimental comonomer blend with 70:30 mass\% bis-GMA/QAMS-3 $\mathrm{PH}$ were used for evaluating the dynamic mechanical behavior under dehydrated and hydrated conditions. Under dehydrated conditions, the 70/30\% bis-GMA/TEGDMA control ( $\mathrm{E}^{\prime}$ $\left.=3.26 \pm 0.44 \mathrm{GPa}, \mathrm{E}^{\prime \prime}=0.48 \pm 0.23 \mathrm{GPa}, \tan \delta=0.27 \pm 0.08\right)$ and the $70 / 30 \%$ bis-GMA/ QAMS $-3{ }_{\mathrm{PH}}$ experimental polymerized resins $\left(\mathrm{E}^{\prime}=2.88 \pm 0.40 \mathrm{GPa}, \mathrm{E}^{\prime \prime}=0.57 \pm 0.25 \mathrm{GPa}\right.$, $\tan \delta$ $=0.34 \pm 0.09$ ) exhibited similar storage and loss moduli and tan $\delta$ values (Fig. 8A) After hydration for 72 hours, the storage modulus $\left(\mathrm{E}^{\prime}=1.58 \pm 0.75 \mathrm{GPa}\right.$ ), loss modulus ( $\mathrm{E}$ $"=0.25 \pm 0.53 \mathrm{GPa}$, $)$ and $\tan \delta(0.19 \pm 0.17)$ of the control bis-GMA/TEGDMA resin decreased significantly, which is indicative of deterioration of the resin matrix. By contrast, the hydrated experimental resin demonstrated higher storage and loss moduli $\left(\mathrm{E}^{\prime}=5.60 \pm 1.87\right.$ $\left.\mathrm{GPa}, \mathrm{E}^{\prime \prime}=1.65 \pm 1.10 \mathrm{GPa}\right)$ and higher $\tan \delta(0.43 \pm 0.30)$, indicating a greater capacity for energy absorption (Fig. 8B). To confirm these results, additional experimental comonomer blends containing 70/30 mass\% non-hydrolyzed QAMS-3 monomer mix and 60/40 mass\% QAMS-3 $3_{\mathrm{PH}}$ were also examined (Figs. 8C-E). Nanodynamic mechanical properties were further improved with a bis-GMA/QAMS-3 $\mathrm{PH}_{\mathrm{PH}}$ mass ratio of 60:40. Under transmission electron microscopy, longitudinal sections prepared from stressed, hydrated specimens showed the presence of electron-dense deposits surrounding a crack tip (Fig. 8F). At high magnification, an interconnecting electron-dense network was identified within that part of the polymer matrix.

\section{Discussion}

Admittedly, the global demand for antimicrobial methacrylate resins is small when compared to antimicrobial polyolefins, polyvinyl chloride, polyurethanes or epoxy resins. Nevertheless, bis-GMA-based resins are widely employed in the dental field as tooth-filling composites. Resin-based tooth-fillings based on current bis-GMA formulations have low service lives in load-bearing parts of the mouth, and demonstrate recurrent decay around filling margins as well as filling fracture, which are the most common reasons for failure [29]. Indeed, the cost of replacing failed tooth-fillings accounts for more than 5 billion dollars per annum in the US alone [30]. Most dental adhesives are applied to carious dentin. Although dentists remove soft bacteria-infected dentin, the remaining dentin is termed 
"caries-affected" dentin. It contains some viable bacteria that can cause secondary caries over time. What is needed are antibacterial adhesives. Several research groups have assed quaternary ammonium compounds to dental adhesives in an attempt to make then antibacterial [31,32]. Because these antibacterial compounds are not covalently linked to the polymer matrix of adhesives, they can leach out of the adhesives overtime, thereby losing their long-time efficiency. The solution for that problem was to use antimicrobial methacrylates that can covalently copolymerize with the adhesive matrix. The only quaternary ammonium antimicrobial methacrylate resin monomer available commercially for dental use is 12-methacryloyloxydodecyl pyridinium bromide, and its application is currently limited to adhesives for adhering composite fillings to tooth structures $[33,34]$. Others have reported successful use of other quaternary ammonium methacrylates in adhesives [35,36]. Apart from the potential to prevent recurrent decay, incorporation of more flexible siloxane linkages in QAMSs may impart additional benefits, such as improved polymerization characteristics and the ability to self-repair damage caused by water sorption and mechanical stress over time. While the current work represents a proof-of-concept, the methanol derived from the SiQAC solvent and further condensation of trimethoxysilanes is a concern in biomedical applications. To circumvent this problem, an ethoxylated version of SiQAC (i.e. 3-(triethoxysilyl)propyldimethyloctadecyl ammonium chloride) has been synthesized that is soluble in ethanol. Residual methanol can also be completely eliminated when 3-methacryloxypropyltriethoxysilane and ethoxylated-SiQAC are employed in the solgel process. Investigations of the dental applications of the ethoxylated versions of QAMS are in order. As the confocal laser scanning microscopy results in the present study indicate that these resins have antifungal activities against Candida albicans, this may permit creation of antibacterial/antifungal partial/full denture bases if QAMS-3 $\mathrm{PH}$ are copolymerized with polymethyl methacrylate. This may prevent malodor and mucosal inflammation in denture patients or in orthodontic patients wearing retainers [37,38]. Additional potential advantages of removal dental prostheses containing QAMS are that the antimicrobial activities are not lost following the wear of the prostheses, and the potential increase in fracture toughness of the polymethyl methacrylate following the incorporation of ten or more mass $\%$ of QAMS-3 in the methyl methacrylate monomer used to fabricate those prostheses (Gong et al., unpublished results). These novel features have to be investigated in detail in future studies.

Because monomeric bis-GMA is highly viscous due to intermolecular hydrogen bonding, TEGDMA is usually added in the range of 30-50 mass \% as a reactive diluent [39]. The polymerization characteristics of QAMS-3 $\mathrm{PH}^{-}$-containing conomomer blends were investigated in the present study, to ensure that they were not inferior to those exhibited by the bis-GMA/TEGDMA control resin blend. For dental methacrylate resins, both a high degree of conversion and minimal polymerization shrinkage are extremely desirable properties. However, they are antagonistic goals, as increased monomer conversion invariably results in greater polymerization shrinkage [39]. In the current study, the use of solvated QAMS-3 $\mathrm{PH}$ as diluent in bis-GMA resins reduces polymerization shrinkage without lowering their degree of conversion. These results are analogous to those obtained when a bifunctional acryloxy phenyl disiloxane was used to replace bis-GMA and TEGDMA as the base monomer in experimental composites [40]. This may be attributed to enhancement in the rate of free radicals diffusion by increased polymer chain mobility. The latter is caused by the flexibility conferred by the siloxane backbone [12], and reduction in comonomer viscosity in a solvated resin system [41]. The increase in hydrophobicity of QAMS-3 $\mathrm{PH}^{-}$ containing resin matrices, as determined by contact angle measurements (Supplementary Information S3) is probably caused by surface re-orientation of the long alkyl chains of the quaternary ammonium functionalities after polymerization, the preferred antimicrobial orientation. A similar increase in hydrophobicity was observed after SiQAC was immobilized on silica nanoparticles [42]. 
According to the Centers for Disease Control and Prevention, more than $60 \%$ of all microbial infections are associated with biofilms [43]. Thus, the antimicrobial activities of polymerized resin disks prepared from comonomer blends with bis-

GMA:TEGDMA:QAMS-3PH mass ratios of 70:30:0, 70:10:20 and 70:0:30 were investigated using single-species biofilms of Streptococcus mutans (ATCC 36558), Actinomyces naeslundii (ATCC 12104) or Candida albicans (ATCC 90028). The first two represent cariogenic oral pathogens that are associated with recurrent decay around tooth fillings [44]. Candida albicans, a common commensal fungus in humans, may be converted to an opportunistic pathogen associated with oral candidiasis in susceptible hosts [45]. The antimicrobial activities of QAMS- $3 \mathrm{PH}^{-}$containing resin are characteristic of biomaterials with passive antimicrobial activity (i.e. contact-killing) [46], as opposed to biomaterials that are designed to release high initial fluxes of antimicrobial agents [47]. However, the longterm microbiocidal potential of the latter is debatable. Bacteria adhesion is the essential step in the formation of biofilms on biomaterial surfaces, and involves an initial instantaneous physicochemical phase, followed by a time-dependent molecular and cellular phase [48]. Although substrate hydrophobicity and high surface positive charges of SiQACfunctionalized resins could have enhanced microbial adhesion during the initial phase of biofilm formation $[7,48]$, microbes along the resin surface were readily killed upon contact due to the presence of surface-oriented long alkyl chains of the quaternary ammonium functionality. These results support the first hypothesis that antibacterial and antifungal activities are retained after QAMS-3 $3_{\mathrm{PH}}$ is co-polymerized with bis-GMA.

Antimicrobial polymers designed for biomedical applications should be minimally cytotoxic to host tissues. In the present study, two complementary strategies were employed to examine the viability of MDPC-23 cells in the presence of QAMS-containing bis-GMA resins. Both strategies have their merits and limitations. The first strategy (MTT assay) evaluated cell metabolic activity, based on the premise that dead cells are incapable of metabolizing tetrazolium salts via mitochondrial dehydrogenases involved in the citric acid cycle and the electron transport chain. Cellular damage invariably results in the loss of the ability of the cell to provide energy for cell function and growth. Unlike necrosis, apoptosis is an active mode of cell death that relies on sustained energy production from cell metabolism for its induction [49]. Thus, tetrazolium salt-based assays may underestimate cellular damage and detect cell death only at the later stage of apoptosis when cellular metabolism is substantially reduced. The second strategy (differential staining) examined plasma membrane alterations (permeability) that were induced by cellular damage. Because dyes stain individual cells, each sample has to be analyzed by flow cytometry or microscopy. In normal cells, the distribution of phospholipids is asymmetric. Plasmamembrane alterations at the cell surface that occur during the initial stages of apoptosis result in translocation of intramembranous phosphatidylserine to the outer leaflet of the plasma membrane. Annexin-V, a calcium-dependent phospholipid-binding protein, has a high affinity for phosphatidylserine. Although it does not bind to normal living cells, Annexin- $\mathrm{V}$ binds to the phosphatidylserine exposed on the surface of apoptotic cells. However, necrotic cells are also labeled by annexin- $V$ upon rupture of their plasma membrane. Thus, for flow cytometry and fluorescence microscopic valuation, it is necessary to control the membrane integrity of the phosphatidylserine-positive cells by double-staining with membrane-impermeable DNA dyes such as ethidium homodimer-III, propidium iodide or 7-Amino-actinomycin D. Cells with altered plasma membrane permeability are stained, whereas undamaged (viable) cells are not stained with dyes that do not penetrate the plasma membrane (exclusion dyes). Conversely, the bisbenzimidazole dye, Hoechst 33342, penetrates the plasma membrane and stains DNA in both viable and non-viable cells. Thus, it is used in confocal laser scanning miscopy imaging as an indicator of the total number of cells in a field of view. The results of the two complementary cell viability assays indicate that QAMS-containing BisGMA-based resins are relatively non-cytotoxic. Because the 
cytotoxicity of TEGDMA has been well documented [50], solvated QAMS-3 $3_{\mathrm{PH}}$ may be used to partially or completely replace TEGDMA as a more biocompatible diluent in bisGMA resin formulations.

Even though water sorption and hydrolysis of ester bonds release alcohols that attract even more water [51] that might tend to plasticize the matrix, the nano-Dynamic Mechanical Analysis results in the present work reveal that both the stiffness and damping properties of polymerized comonomer blends containing QAMS- $3 \mathrm{PH}$ are improved after hydration. The increase in stiffness of hydrolyzed bis-GMA:QAMS- $3_{\mathrm{PH}}$ resin indicates that condensation polymerization and silicate production increase the nanomechanical properties of these resins, thereby supporting the second tested hypothesis. We speculate that addition of partially-hydrolyzed QAMS to bisGMA-based resins may translate into an improved methacrylate resin system that is stiffer (i.e. $8 \mathrm{GPa}$ ) than most commercially available methacrylate resins (2-4 GPa), upon continuing hydrolysis and condensation reactions of the QAMS. Although such a process is dependent upon water sorption into the polymerized resin matrix, the increase in stiffness upon water aging may have an advantage when partially-hydrolyzed QAMS-containing BisGMA resins are formulated into resin composites. The initial, relatively low stiffness values and the reduction in polymerization shrinkage of these composites may result in less shrinkage stress being transferred to the developing adhesive bond; such bonds would tend to have less tendencies to debond during light-curing. After water sorption, hydrolysis of the ester into silanol groups would permit a time-dependent increase in stiffness due to condensation polymerization. Such a hypothesis has to be tested in the future, after incorporation of glass fillers into the QAMS-containing bis-GMA-based resin formulations.

The interconnecting electron-dense network identified within polymer matrix surrounding crack-tip under transmission electron microscopy probably represents the results of continued hydrolysis of QAMS-3 $\mathrm{PH}$ and its subsequent polycondensation at physiologic $\mathrm{pH}$ to produce a 3-D organic modified silicate phase (ORMOSIL), as water sorption occurs more readily under stress in the vicinity of the crack-tip. Because no additional siloxanebased macromonomers and catalysts are available, the microscopic cracks cannot be filled and thereby cannot heal autonomously, in the strictest sense [15]. Nevertheless, polycondensation of a siloxane cross-linked silicate network in response to environmental damage offers a potential self-repair mechanism wherein catastrophic failure may be postponed by energy dissipation through crack-path deflection and meandering, or by cracktip shielding via transformation toughening [52]. Thermoset organic polymers are often used as the matrix in structural composites because of their high stiffness and strength. However, their low toughness, especially in the presence of sharp notches, poses problems to the longevity of these composites. Although transformation toughening occurs readily in zirconia-based ceramics, it is only seen in crystalline and semi-crystalline polymers [53,54]. For amorphous thermoset organic polymers, particulate crystalline polymer phases have to be included to achieve transformation toughening [55]. Further work should be performed to examine the fracture toughness (R-curve behavior) and fatigue crack growth responses [56] of bis-GMA/QAMS- $3_{\mathrm{PH}}$ resins after aqueous aging and cyclic loading to validate this potential self-repair mechanism.

\section{Conclusion}

A quaternary ammonium silane-functionalized methacrylate (QAMS) represents an example of antimicrobial macromonomers synthesized by sol-gel chemistry and possesses flexible Si-O-Si bonds. A partially-hydrolyzed resin formulation containing QAMS co-polymerized with bis-GMA retains kill-on-contact microbiocidal activities, which should contribute to prevent resin-based tooth-filling failure caused by caries recurrence. Apart from the 
potential to prevent recurrent decay, incorporation of more flexible siloxane linkages in QAMSs may impart additional benefits, such as improved polymerization characteristics and the ability to self-repair damage caused by water sorption and mechanical stress over time.

\section{Supplementary Material}

Refer to Web version on PubMed Central for supplementary material.

\section{Acknowledgments}

This work was supported by grant R01 DE015306-06 from NIDCR (PI. David Pashley) and the ERA award from Georgia Health Sciences University (PI. Franklin Tay). We thank Michelle Barnes for secretarial support, Dr. William L. Jarrett for ${ }^{29} \mathrm{Si}$ NMR spectroscopy, and Jeevanie Epasinghe for biofilm preparation.

\section{References}

1. Kenawy, El-R.; Worley, SD.; Broughton, R. The chemistry and applications of antimicrobial polymers: a state-of-the-art review. Biomacromolecules. 2007; 8:1359-1384. [PubMed: 17425365]

2. Markarian J. Materials handling equipment for the compounding plant. Plast Addit Compd. 2009; 11:18-21.

3. Global Industry Analysts, Inc. http://www.prweb.com/releases/healthcare_antimicrobial/ plastics_biocides/prweb8831439.htm

4. Isquith AJ, Abbott EA, Walters PA. Surface-bonded antimicrobial activity of an organosilicon quaternary ammonium chloride. Appl Microbiol. 1972; 24:859-863. [PubMed: 4650597]

5. Gottenbos B, van der Mei HC, Klatter F, Nieuwenhuis P, Busscher HJ. In vitro and in vivo antimicrobial activity of covalently coupled quaternary ammonium silane coatings on silicone rubber. Biomaterials. 2002; 23:1417-1423. [PubMed: 11829437]

6. Oosterhof JJ, Buijssen KJ, Busscher HJ, van der Laan BF, van der Mei HC. Effects of quaternary ammonium silane coatings on mixed fungal and bacterial biofilms on tracheoesophageal shunt prostheses. Appl Environ Microbiol. 2006; 72:3673-3677. [PubMed: 16672516]

7. Ahlström B, Thompson RA, Edebo L. The effect of hydrocarbon chain length, $\mathrm{pH}$, and temperature on the binding and bactericidal effect of amphiphilic betaine esters on Salmonella typhimurium. APMIS. 1999; 107:318-324. [PubMed: 10223305]

8. Saif MJ, Anwar J, Munawar MA. A novel application of quaternary ammonium compounds as antibacterial hybrid coating on glass surfaces. Langmuir. 2009; 25:377-379. [PubMed: 19115872]

9. Blizzard, JD.; Kimmerling, KA. U S Prov Pat Appl. 61/527,231. 2011.

10. Nicole L, Rozes L, Sanchez C. Integrative approaches to hybrid multifunctional materials: from multidisciplinary research to applied technologies. Adv Mater. 2010; 22:3208-3214. [PubMed: 20552603]

11. Matyjaszewski K, Tsarevsky NV. Nanostructured functional materials prepared by atom transfer radical polymerization. Nat Chem. 2009; 1:276-288. [PubMed: 21378870]

12. Owen MJ. The Surface Activity of Silicones: A Short Review. Ind Eng Chem Prod Res Dev. 1980; 19:97-103.

13. Sideridou I, Achilias DS, Spyroudi C, Karabela M. Water sorption characteristics of light-cured dental resins and composites based on Bis-EMA/PCDMA. Biomaterials. 2004; 25:367-376. [PubMed: 14585725]

14. Fahmy AA, Hunt JC. Stress dependence of water diffusion in epoxy resin. Polym Compos. 1980; 1:77-80.

15. Burattini S, Greenland BW, Chappell D, Colquhoun HM, Hayes W. Healable polymeric materials: a tutorial review. Chem Soc Rev. 2010; 39:1973-1985. [PubMed: 20502798]

16. Cory DG, Ritchey WM. Suppression of signals from the probe in block decay spectra. J Magn Reson. 1988; 80:128-132. 
17. Rueggeberg FA. State-of-the-art: dental photocuring-a review. Dent Mater. 2011; 27:39-52. [PubMed: 21122903]

18. Ruyter IE, Svendsen SA. Remaining methacrylate groups in composite restorative materials. Acta Odontol Scand. 1978; 36:75-82. [PubMed: 274063]

19. Calheiros FC, Daronch M, Rueggeberg FA, Braga RR. Degree of conversion and mechanical properties of a BisGMA:TEGDMA composite as a function of the applied radiant exposure. J Biomed Mater Res B Appl Biomater. 2008; 84:503-509. [PubMed: 17635039]

20. Watts DC, Cash AJ. Kinetic measurements of photo-polymerization contraction in resins and composites. Meas Sci Technol. 1991; 2:788-794.

21. Solé A, Mas J, Esteve I. A new method based on image analysis for determining cyanobacterial biomass by CLSM in stratified benthic sediments. Ultramicroscopy. 2007; 107:669-673. [PubMed: 17350172]

22. Mantellini MG, Botero TM, Yaman P, Dennison JB, Hanks CT, Nör JE. Adhesive resin induces apoptosis and cell-cycle arrest of pulp cells. J Dent Res. 2003; 82:592-596. [PubMed: 12885841]

23. Edmondson JM, Armstrong LS, Martinez AO. A rapid and simple MTT-based spectrophotometric assay for determining drug sensitivity in monolayer cultures. J Tissue Cult Meth. 1988; 11:15-17.

24. Ryou H, Niu LN, Dai L, Pucci CR, Arola DD, Pashley DH, Tay FR. Effect of biomimetic remineralization on the dynamic nanomechanical properties of dentin hybrid layers. J Dent Res. 2011; 90:1122-1128. [PubMed: 21730254]

25. Achilias DD, Karabela MM, Sideridou ID. Thermal degradation of light-cured dimethacrylate resins. Part I. Isoconversional kinetic analysis. Thermochim Acta. 2008; 472:74-83.

26. Leyden DE, Shreedhara-Murphy RSS, Blitz JP, Atwater JB, Rachetti A. Reflectance FTIR investigations of the reactions of silanes on silica surfaces. Mikrochim Acta. 1988; 11:53-56.

27. Regoli IC, Cavalheiro CCS, Neumann MG, Cavalheiro ETG. Thermal decomposition of copolymers used in dental resins formulations photocured by ultra blue IS. J Appl Polym Sci. 2007; 105:3295-3300.

28. Achilias DD, Karabela MM, Sideridou ID. Thermal degradation of light-cured dimethacrylate resins. Part I. Isoconversional kinetic analysis. Thermochim Acta. 2008; 472:74-83.

29. Sarrett DC. Clinical challenges and the relevance of materials testing for posterior composite restorations. Dent Mater. 200; 21:9-20. [PubMed: 15680997]

30. Jokstad A, Bayne S, Blunck U, Tyas M, Wilson N. Quality of dental restorations. FDI Commission Projects 2-95. Int Dent J. 2001; 51:117-158. [PubMed: 11563679]

31. Namba N, Yoshida Y, Nagaoka N, Takashima S, Matsuura-Yoshimoto K, Maeda H, et al. Antibacterial effect of bactericide immobilized in resin matrix. Dent Mater. 2009; 25:424-430. [PubMed: 19019421]

32. Yiu CK, Hiraishi N, Tay FR, King NM. Effect of chlorhexidine incorporation into dental adhesive resin on durability of resin-dentin bond. J Adhes Dent. 2012 [Epub ahead of print].

33. Imazato S, Tay FR, Kaneshiro AV, Takahashi Y, Ebisu S. An in vivo evaluation of bonding ability of comprehensive antibacterial adhesive system incorporating MDPB. Dent Mater. 2007; 23:110116.

34. Imazato S. Bio-active restorative materials with antibacterial effects: new dimension of innovation in restorative dentistry. Dent Mater. 2009; 28:11-19.

35. Xiao YH, Chen JH, Fang M, Xing XD, Wang H, Wang YJ, et al. Antibacterial effects of three experimental quaternary ammonium salt (QAS) monomers on bacteria associated with oral infections. J Oral Sci. 2008; 50:323-327. [PubMed: 18818469]

36. Li F, Chai ZG, Sun MN, Wang F, Ma S, Zhang L, Fang M, Chen JH. Anti-biofilm effect of dental adhesive with cationic monomer. J Dent Res. 2009; 88:372-376. [PubMed: 19407160]

37. Regis RR, Zanini AP, Della Vecchia MP, Silva-Lovato CH, Oliveira Paranhos HF, de Souza RF. Physical properties of an acrylic resin after incorporation of an antimicrobial monomer. $\mathrm{J}$ Prosthodont. 2011; 20:372-379. [PubMed: 21627706]

38. Dhir G, Berzins DW, Dhuru VB, Periathamby AR, Dentino A. Physical properties of denture base resins potentially resistant to Candida adhesion. J Prosthodont. 2007; 16:465-472. [PubMed: $17672838]$ 
39. Venhoven BA, de Gee AJ, Davidson CL. Polymerization contraction and conversion of lightcuring BisGMA-based methacrylate resins. Biomaterials. 1993; 14:871-875. [PubMed: 8218741]

40. Lai, JH. Organosilicon dental composite restorative materials. United States Patent Office. 5,081,164. 1992 .

41. Holmes RG, Rueggeberg FA, Callan RS, Caughman F, Chan DC, Pashley DH, Looney SW. Effect of solvent type and content on monomer conversion of a model resin system as a thin film. Dent Mater. 2007; 23:1506-1512. [PubMed: 17368744]

42. Song J, Kong H, Jang J. Bacterial adhesion inhibition of the quaternary ammonium functionalized silica nanoparticles. Colloids Surf B Biointerfaces. 2011; 82:651-656. [PubMed: 21115282]

43. Lewis K. Riddle of biofilm resistance. Antimicrob Agents Chemother. 2001; 45:999-1007. [PubMed: 11257008]

44. Mo SS, Bao W, Lai GY, Wang J, Li MY. The microfloral analysis of secondary caries biofilm around Class I and Class II composite and amalgam fillings. BMC Infect Dis. 2010; 10:241. [PubMed: 20712908]

45. Kim J, Sudbery P. Candida albicans, a major human fungal pathogen. J Microbiol. 2011; 49:171177. [PubMed: 21538235]

46. Ferreira L, Zumbuehl A. Non-leaching surfaces capable of killing microorganisms on contact. J Mater Chem. 2009; 19:7796-7806.

47. Rodrigues, LR. Inhibition of bacterial adhesion on medical devices. In: Linke, D.; Goldman, A., editors. Bacterial adhesion. New York: Springer; 2011. p. 351-367.

48. Katsikogianni M, Missirlis YF. Concise review of mechanisms of bacterial adhesion to biomaterials and of techniques used in estimating bacteria-material interactions. Eur Cells Mater. 2004; 8:37-57.

49. Wyllie AH, Kerr JF, Currie AR. Cell death: the significance of apoptosis. Int Rev Cytol. 1980; 68:251-306. [PubMed: 7014501]

50. Stanislawski L, Lefeuvre M, Bourd K, Soheili-Majd E, Goldberg M, Périanin AJ. TEGDMAinduced toxicity in human fibroblasts is associated with early and drastic glutathione depletion with subsequent production of oxygen reactive species. Biomed Mater Res A. 2003; 66:476-482.

51. Malacarne-Zanon J, Pashley DH, Agee KA, Foulger S, Alves MC, Breschi L, et al. Effects of ethanol addition on the water sorption/solubility and percent conversion of comonomers in model dental adhesives. Dent Mater. 2009; 25:1275-1284. [PubMed: 19592083]

52. Ritchie RO. Mechanisms of fatigue crack propagation in metals, ceramics and composites: Role of crack tip shielding. Mater Sci Eng A. 1988; 103:15-28.

53. Karger-Kocsis J. How does "phase transformation toughening" work in semicrystalline polymers? Polym Eng Sci. 1996; 36:203-210.

54. Galeski A. Strength and toughness of crystalline polymer systems. Prog Polym Sci. 2003; 28:1643-1699.

55. Kim JK, Robertson RE. Toughening of thermoset polymers by rigid crystalline particles. J Mater Sci. 1992; 27:161-174.

56. Kruzic JJ. Predicting fatigue failures. Science. 2009; 325:156-158. [PubMed: 19589990]

\section{Appendix A. Supplementary data}

Supplementary information related to this article can be found online.

\section{Appendix B. Figures with essential color discrimination}

Figures in this article are difficult to interpret in black and white. The full color images can be found in the on-line version. 


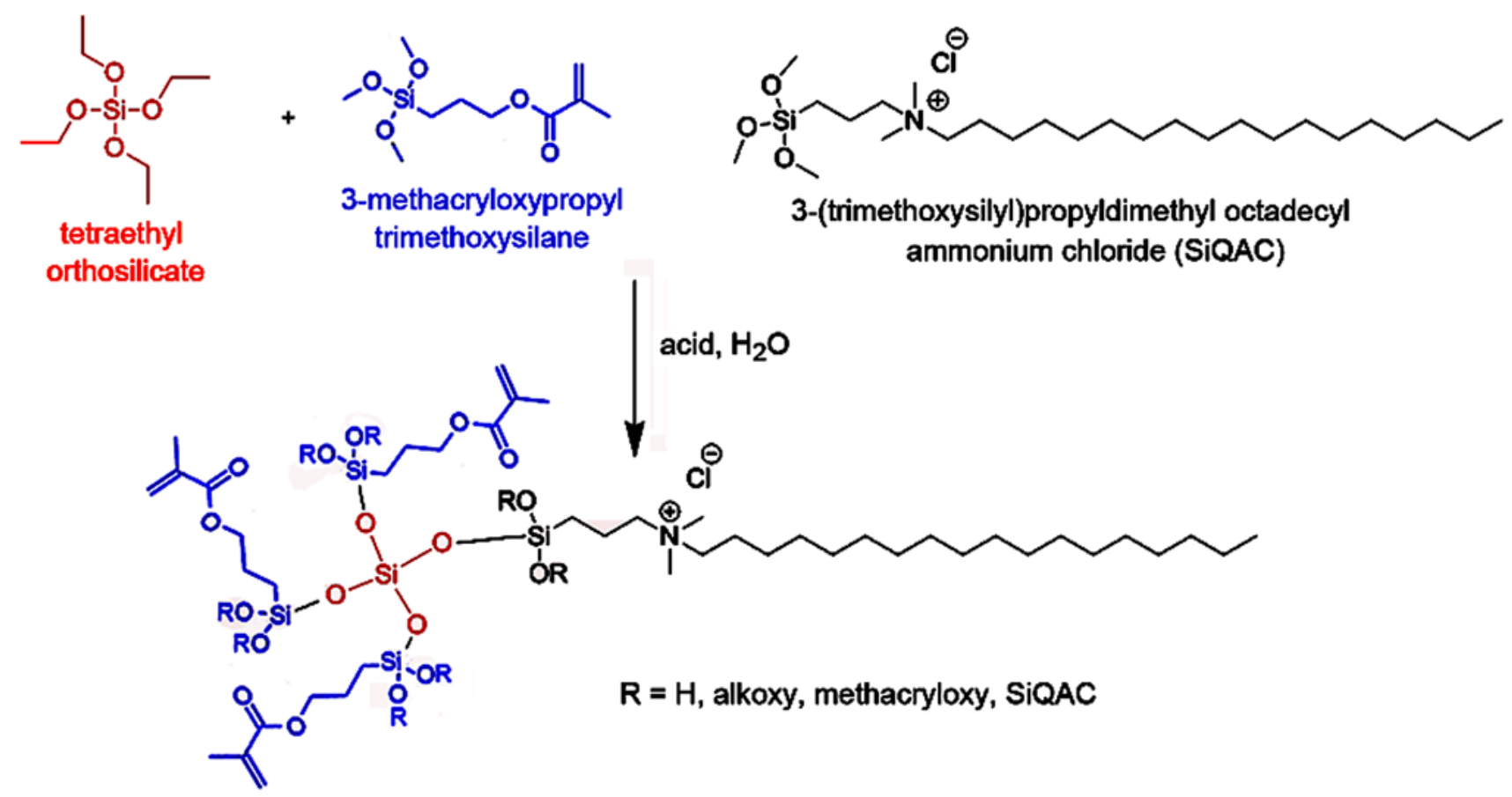

Figure 1.

Reaction scheme for synthesizing QAMS using tetra-alkoxysilane as anchoring unit. Depending on the molar ratio of the two trialkoxysilanes, macromonomers with monofunctional (QAMS-1), bifunctional (QAMS-2) or trifunctional methacryloxy functionalities (QAMS-3) may be produced. 

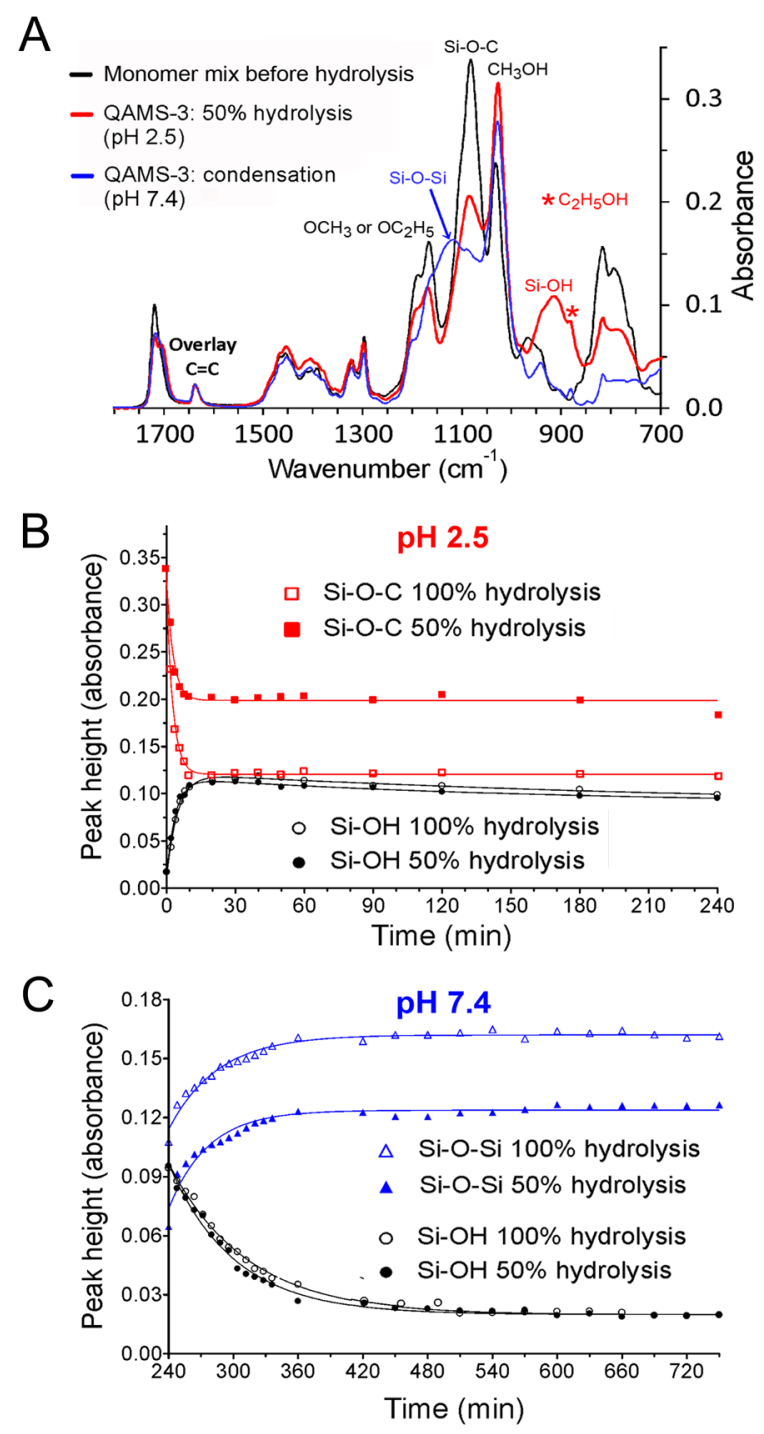

Figure 2.

Hydrolysis and condensation kinetics of QAMS-3 monitored by ATR-FTIR. A. Infrared spectra of the monomer mix for preparing QAMS-3, after partial hydrolysis of the monomer mix at $\mathrm{pH} 2.5$ and after condensation at $\mathrm{pH}$ 7.4. B. Hydrolysis kinetics of completely- and partially-hydrolyzed QAMS-3 at pH 2.5. Plots represent changes in peak heights of the Si$\mathrm{O}-\mathrm{C}$ band at $1082 \mathrm{~cm}^{-1}$ and $\mathrm{Si}-\mathrm{OH}$ band at $914 \mathrm{~cm}^{-1}$. C. Condensation kinetics of completely- and partially-hydrolyzed QAMS-3 at $\mathrm{pH}$ 7.4. Plots represent changes in peak heights of the Si-O-Si band at $1117 \mathrm{~cm}^{-1}$ and $\mathrm{Si}-\mathrm{OH}$ band at $914 \mathrm{~cm}^{-1}$. 
A

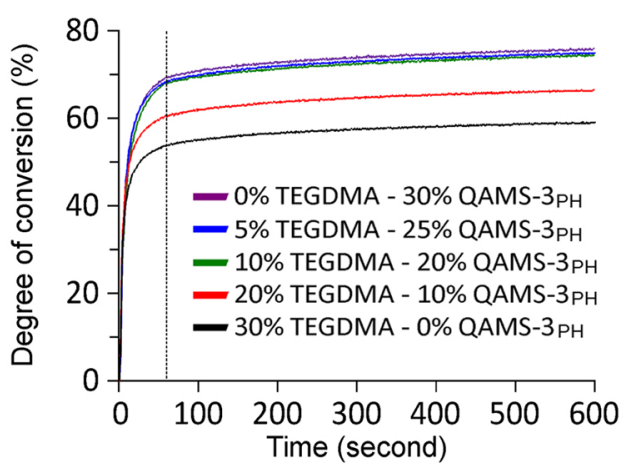

C

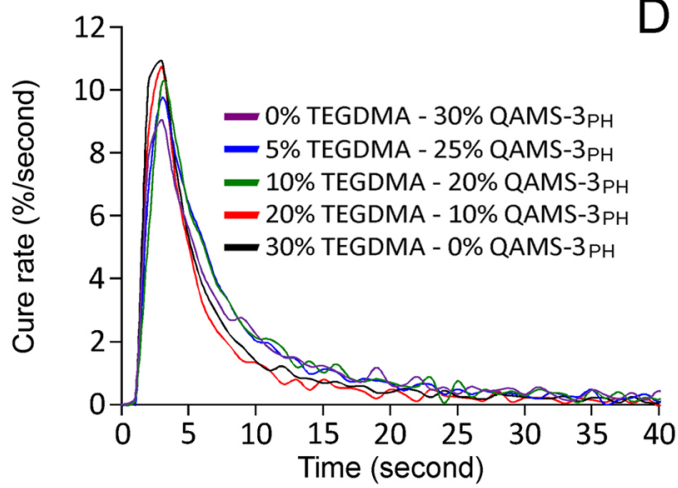

$\mathrm{B}$
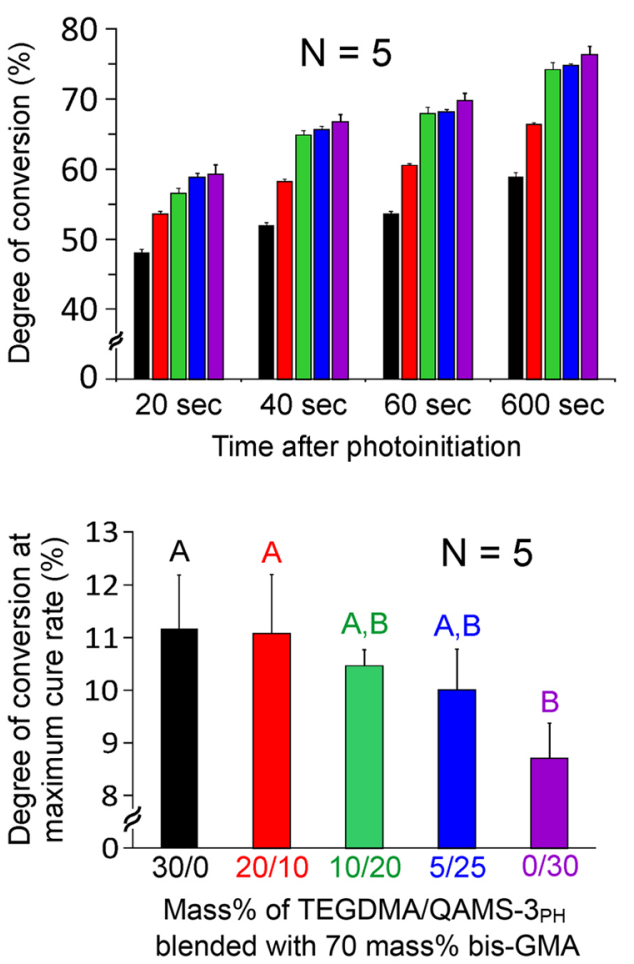

Figure 3.

Kinetics of monomer conversion. A. Conversion values increased as the concentration of TEGDMA diluent was reduced and replaced by equivilent amounts of QAMS- $3 \mathrm{PH}$. Dotted vertical line at 60 seconds represents termination of light curing. B. Conversion values at specific time points among the five comonomer blends. This figure shows the increase in degree of monomer conversion at each time point with respect to increasing QAMS- $3 \mathrm{PH}$ concentration. From the cure rate $(\mathbf{C})$, it can be seen that there were two distinct phases in the polymerization process: an auto-accleration phase and an auto-deceleration phase. Curing of the 5 comonomer blends peaks at a maximum rate from $9-11 \%$ per second. This peaks occurs very eary in the conversion process, that is, within the first 3-4 seconds. D. Degree of conversion at maximum cure rate. Groups that are labeled with the same upper case letters are not statistically significant $(p>0.05)$. A clear trend of decreasing conversion at maximal cure rate with respect to increasing QAMS- $3 \mathrm{PH}$ concentration is evident for the materials tested. 

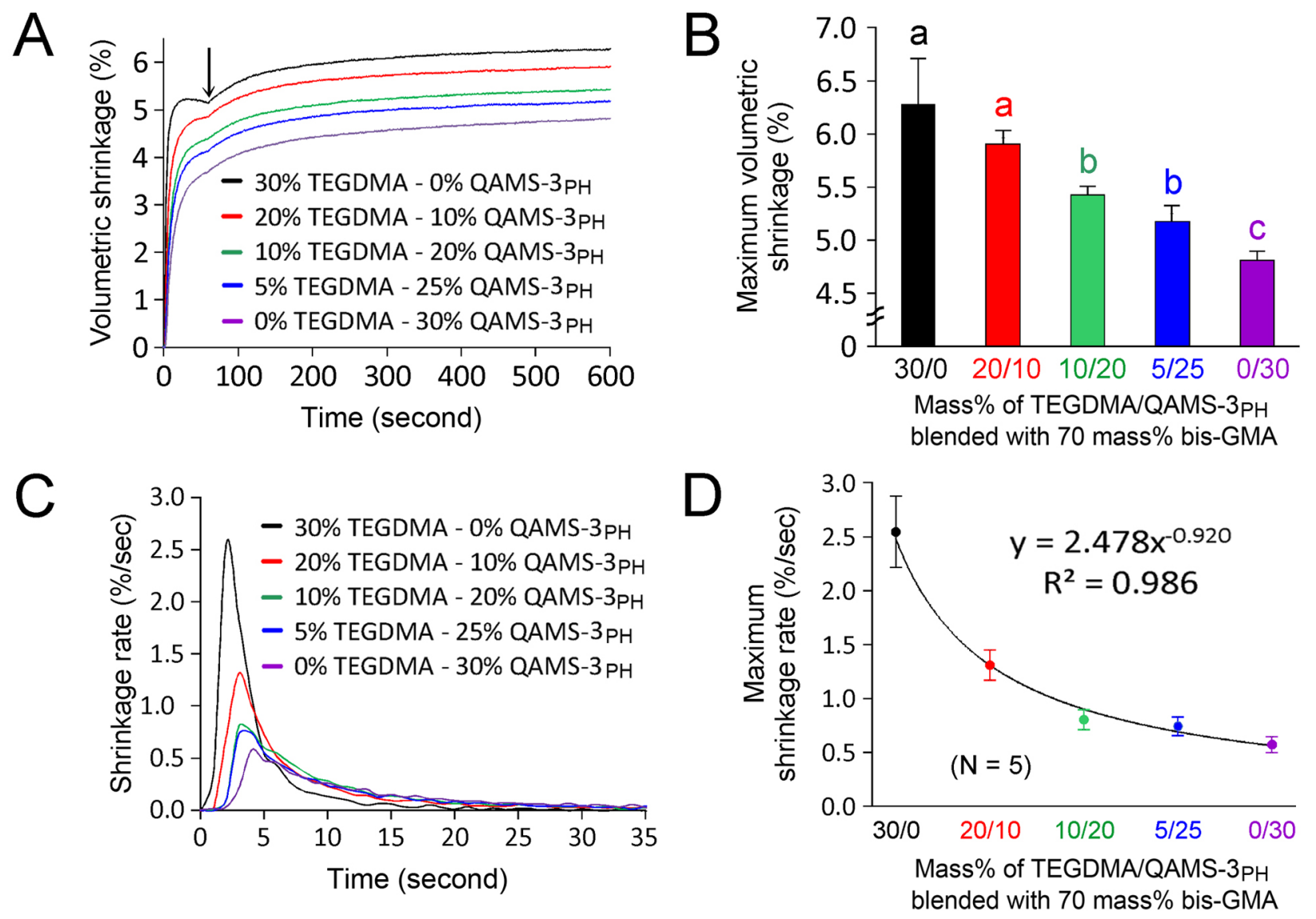

Figure 4.

Kinetics of polymerization shirnkage. A. The five bis-GMA comonomer blends all demonstrated polymerization shrinkage when exposed to visible light. With the exception of an initial expansion caused by the heat generated during light exposure (arrow), polymerization shrinkage continued to increase until a maximum shrinkage value was achieved for each rspective resin. B. Maximum volumetric shrinkage among the five comonomer blends. Groups that are labeled with the same low case letters are not statistically significant $(\mathrm{p}>0.05)$. C. Changes in shrinkage rate with time. Similar to the conversion kinetcs in S-4A, two distinct phases in the polymerization process are evident, with the highest shrinkage rate occurring between 3-5 seconds before auto-decleration occurred. D. A powder regression model provides an excellent fit (adjusted $\mathrm{R}^{2}=0.986 ; \mathrm{p}<$ 0.01 ) for the relation between the maximum shrinkage rate and increases in QAMS- $3 \mathrm{PH}$ concentration. 

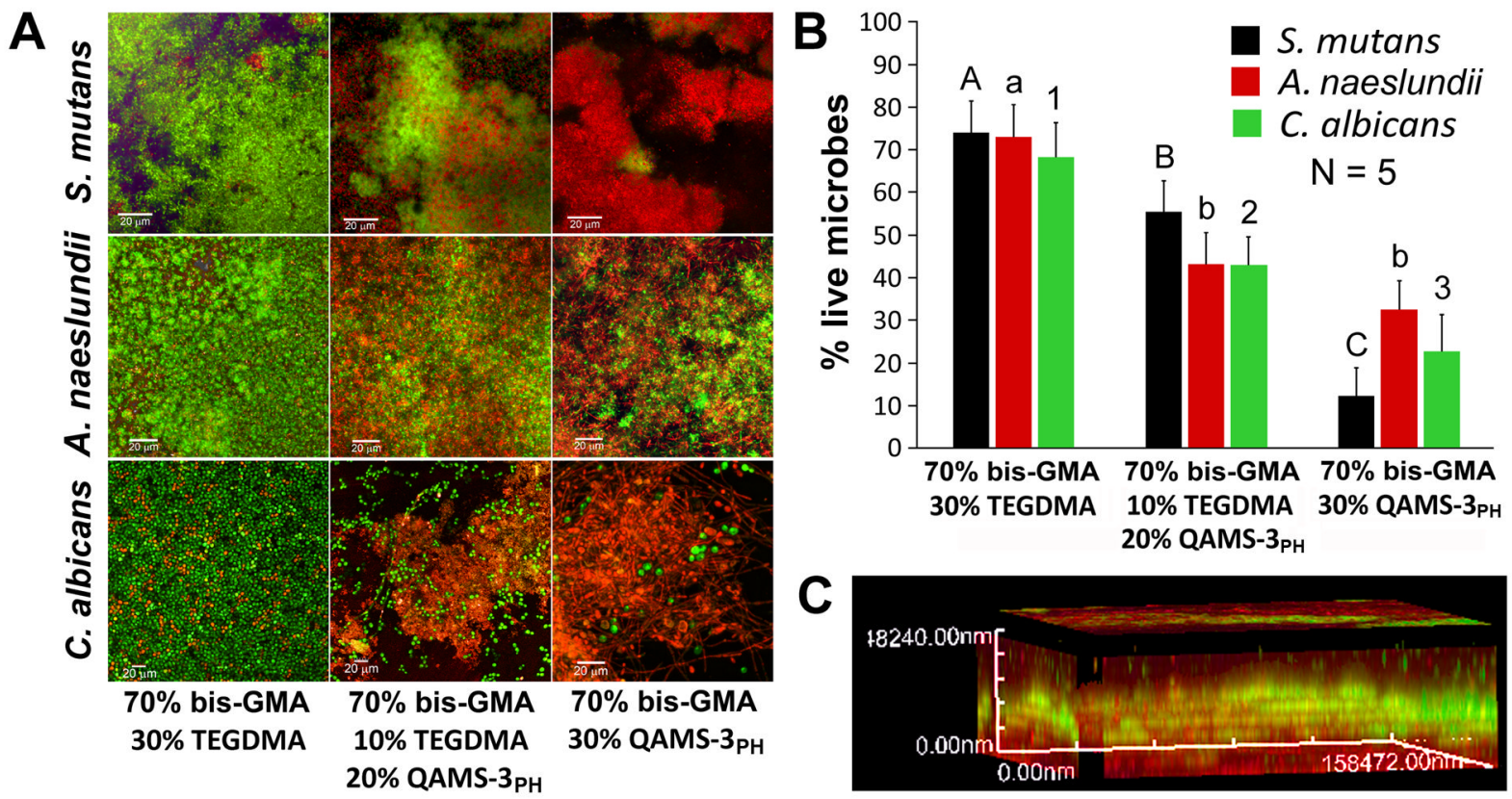

Figure 5.

Antimicrobial activities of polymerized resin containing QAMS-3 $3_{\mathrm{PH}}$. A. Confocal laser scanning microscopy images (2-D overlay projections) of BacLight-stained 48-hour microbial biofilms (live-green; dead-red) grown on resin disks with bisGMA:TEGDMA:QAMS-3 ${ }_{\mathrm{PH}}$ mass ratios of 70:30:0, 70:10:20 and 70:0:30 (bar=20 $\left.\mu \mathrm{m}\right)$.

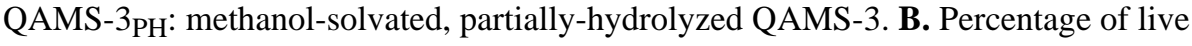
microbes within the respective single-species biofilms. For each species, groups identified with the same designator are not statistically significant $(\mathrm{p}>0.05)$. C. Three-dimensional reconstruction of a $Z$-stack of images taken from a BacLight-stained $A$. naeslundii biofilm

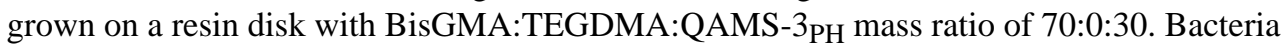
in contact with resin surface were non-viable (red), while those within the body of the biofilm remained viable (green). 

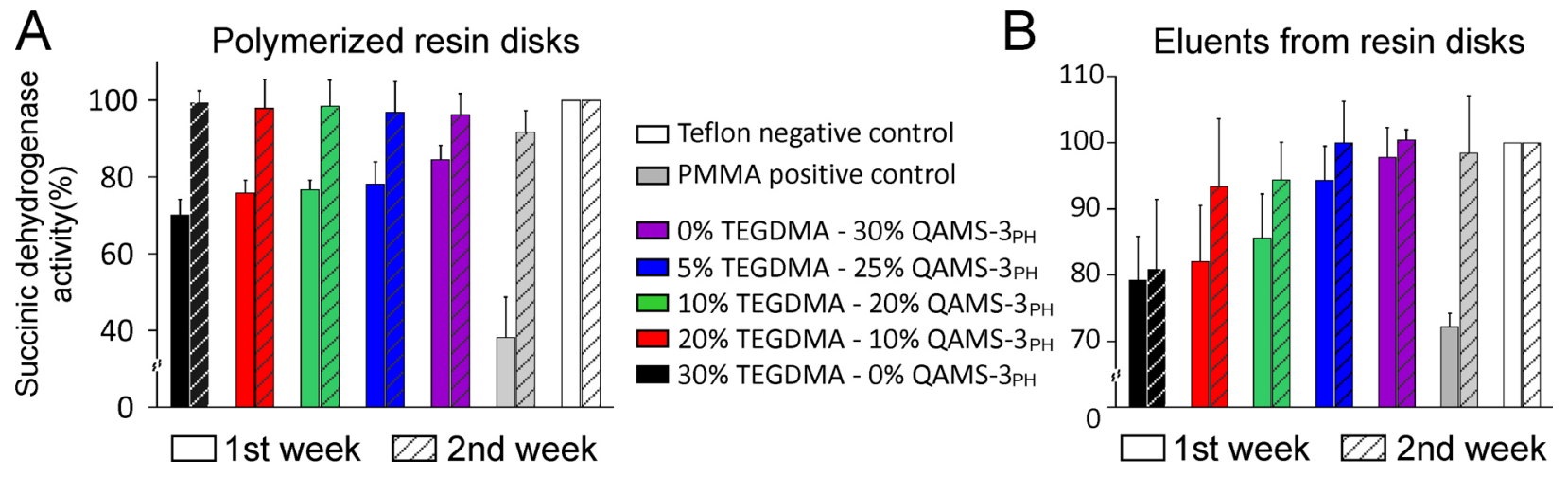

Figure 6.

Mitochondrial succinic dehydrogenase activities (normalized to Teflon negative control $100 \%$ ) of MDPC-23 cells after exposure to $\mathbf{A}$ ) polymerized resin disks prepared from the 5 comonomer blends and the polymethacrylate (PMMA) positive control at two time-periods, and $\mathbf{B}$ ) eluents from the resin disks (1:10 dilution) at the two time-periods. Initially cytotoxicity was identified from the resin disks at the first week but not at the second week, after extraction of toxic components from the polymerized resins. By contrast, the eluents derived from these resins were considerably more cytotoxic. After the second week cycle, eluents derived from polymerized resins with bis-GMA:TEGDMA:QAMS- $3_{\mathrm{PH}}$ mass ratios of 70:5:25 and 70:0:30 were as biocompatible as the Teflon negative control. 

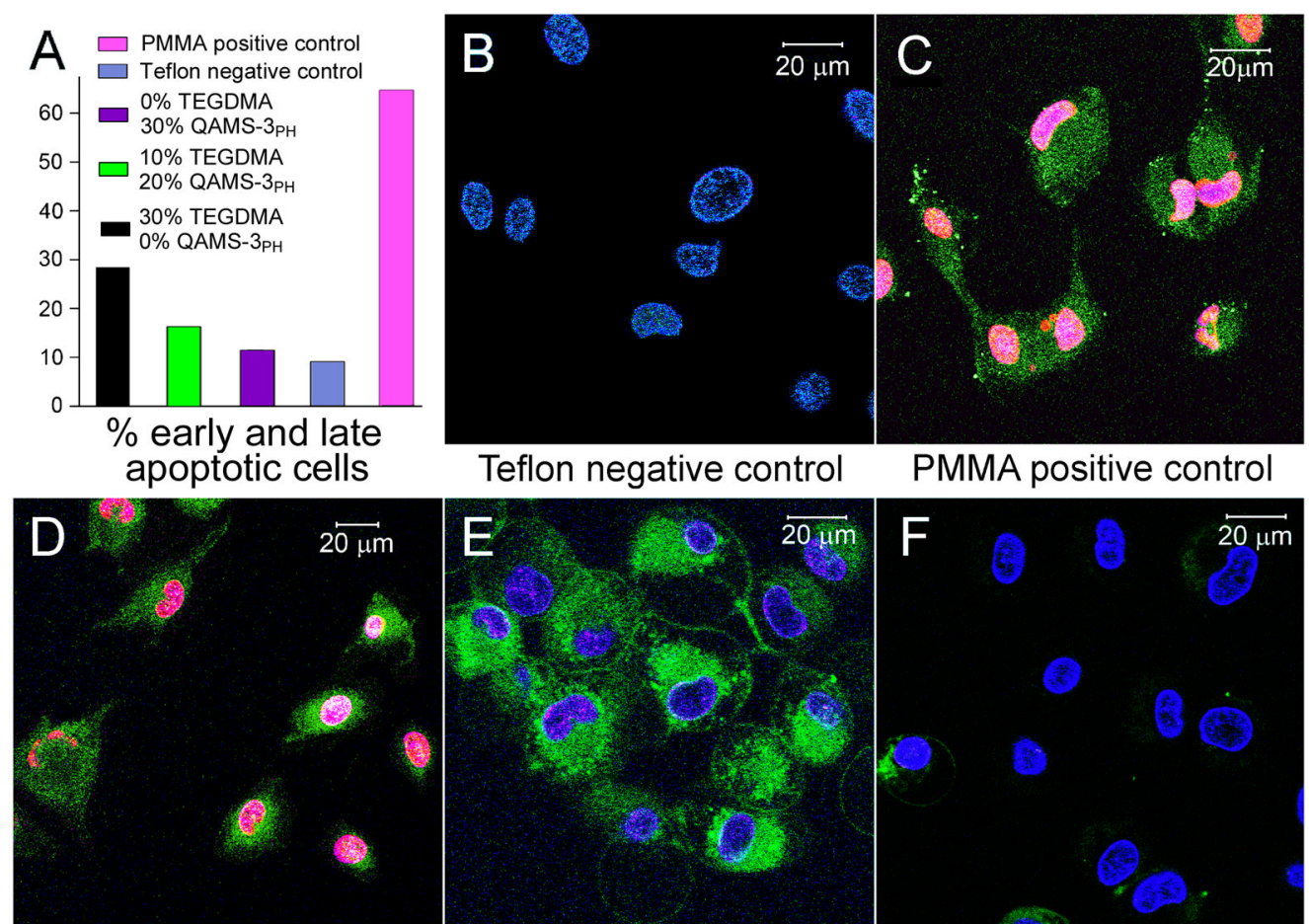

Teflon negative control

PMMA positive control
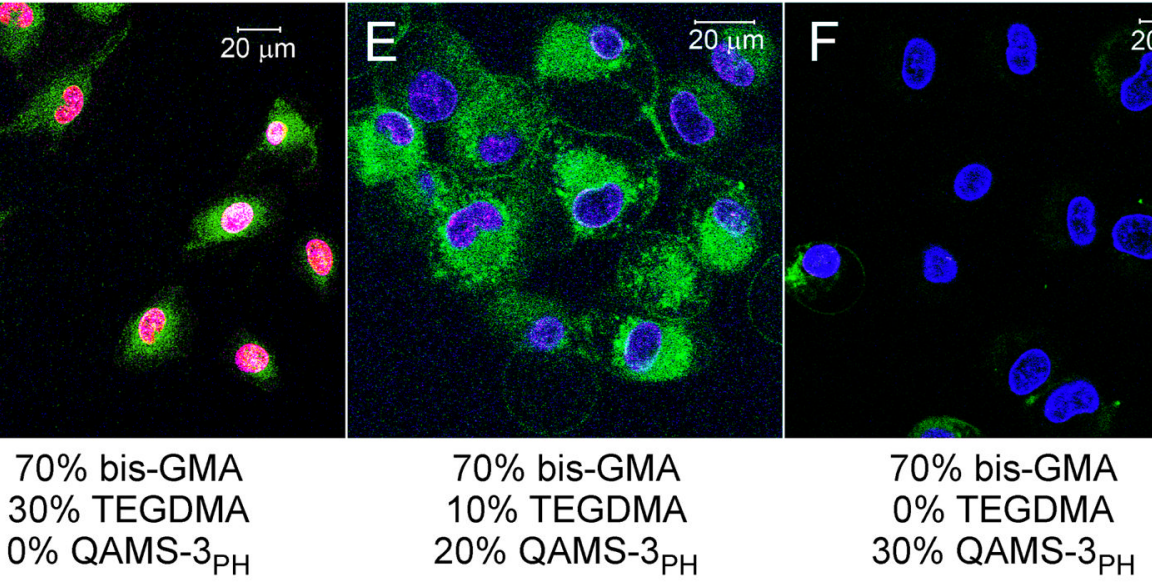

Figure 7.

A. Distribution of early and late apoptotic MDPC-23 cells, after exposure to i) Teflon negative control; ii) Polymethyl methacrylate (PMMA) positive control; iii) Polymerized resin composed of bis-GMA:TEGDMA:QAMS-3 ${ }_{\mathrm{PH}}$ with a mass ratio of 70:30:0; iv) Polymerized resin composed of bis-GMA:TEGDMA:QAMS-3 ${ }_{\mathrm{PH}}$ with a mass ratio of 70:10:20; and v) Polymerized resin composed of bis-GMA:TEGDMA:QAMS-3 $\mathrm{PH}$ with a mass ratio of 70:0:30. The presence of later apoptotic cells even in the negative control group may be attributed to membrane damage to some of the cells (hence, stainable with Annexin-V) when trypsin was employed for cell detachment from the culture plates. Despite this limitation, comparison of the percentage of early and late apoptotic cells shows that the 70:0:30 polymerized resin group has the lowest \% of apoptotic cells among the three resin groups. B-F. Two-photon laser fluorescence microscopy imaging of MDPC-23 cells after exposure to eluents derived from 5 groups. The nuclei of healthy cells were stained positively with Hoescht 33342 (stains DNA of both vital and non-vital cells; blue fluorescence) only. The nuclei of dead cells were stained also positively with ethidium homodimer-III (Etd-III, non-vital DNA marker; red fluorescence). Merging of the channels results in pink nuclei due to combination of the blue and red fluorescence. The cytoplasm of apoptotoic cells were stained positively with FITC-Annexin V (stains cytoplasmic phosphatidylserine; green fluorescence). B. Only healthy cells (stained by Hoechst only, not by FITC-Annexin V and EtD-III) are seen in the Teflon negative control (absence of apoptosis or necrosis). C. Cells were stained blue, green and red in the PMMA positive control, which is indicative of late apoptotic cells or dead cells progressing from the apoptotic cell populations. D. Similar dead cells were seen in the experimental resin group with bis-GMA/TEGDMA/QAMS-3 ${ }_{\mathrm{PH}}$ mass ratio of 70:30:0. E. Early apoptotic cells (stained both blue and green) observed in the in the experimental resin group with bis-GMA/ 
TEGDMA/QAMS-3 $3_{\mathrm{PH}}$ mass ratio of 70:10:20. F. Most of the cells are healthy (stained blue only) in the experimental resin group with bis-GMA/TEGDMA/QAMS-3 $\mathrm{PH}$ mass ratio of 70:0:30. Some early apoptotic cells are also present. 
A

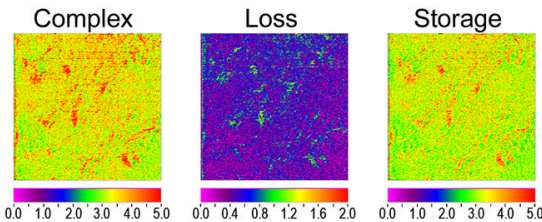

bisGMA/TEGDMA (70:30 mass $\%$ )
Before hydration

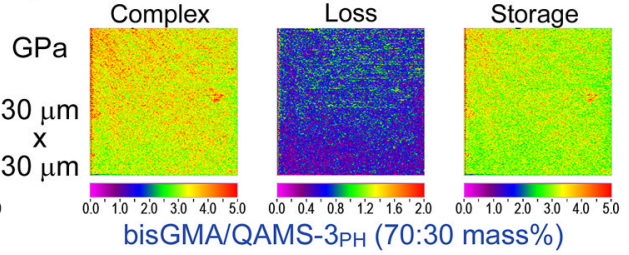

B

After hydration for $\mathbf{7 2}$ hours

Complex
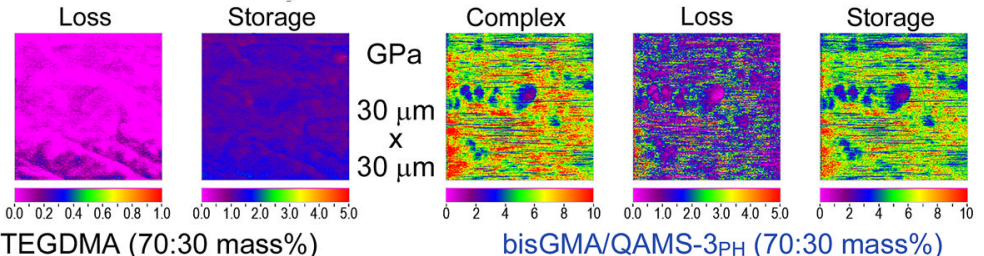

C

Complex Modulus

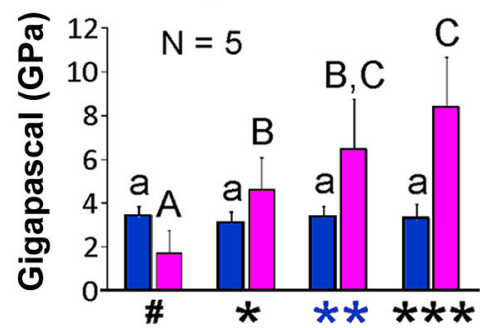

Before hydration

E

Storage Modulus

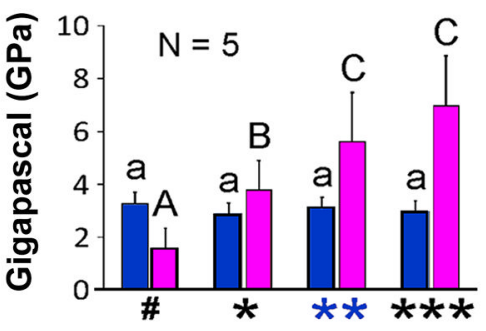

D

Loss Modulus

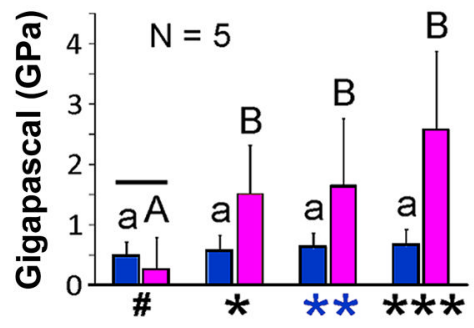

After hydration for 72 hours

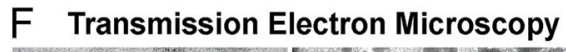

Figure 8.

Dynamic mechanical behavior (complex modulus, loss modulus and storage modulus) under dehydrated and hydrated conditions. A-B. Representative mechanical property maps of polymerized resins prepared from control bis-GMA/TEGDMA and experimental bis-GMA/ QAMS-3 ${ }_{\mathrm{PH}}$ (both 70:30 mass\%) before (A) and after (B) hydration. Note difference in scale between the control and experimental resins in B. QAMS-3 $\mathrm{PH}_{\text {: }}$ methanol-solvated, partiallyhydrolyzed QAMS-3. C-E. Complex modulus (C), loss modulus (D) and storage modulus (E) of the control and experimental groups. Group designations along the horizontal axis \#:bisGMA/TEGDMA (70:30 mass\%); *:bisGMA/QAMS-3 monomer mix (70:30 mass\%); **: bis-GMA/QAMS-3PH (70:30 mass $\%)$; ***: bis-GMA/QAMS-3 ${ }_{\mathrm{PH}}(60: 40$ mass $\%)$. For each material property, same lower-case designations in "before hydration" groups denote no significant difference. Same upper-case designations in "after hydration" denote no significant difference. For each "resin composition", horizontal bar over the two "hydration 
modes" denotes no-significant difference. F. Left: Transmission electron microscopy of phosphotungstic acid-stained, stressed-and-hydrated experimental resin (bis-GMA/ QAMS- $3_{\mathrm{PH}}$, mass ratio:70:30) showing electron-dense phases (asterisks) deposited around a crack-tip (arrow). Right: High magnification of an asterisked region revealing an interconnecting network of probable organic modified silicate condensation products (arrowhead). 